\title{
Famotidine and Celecoxib COVID-19 Treatment Without and With Dexamethasone; Retrospective Comparison of Sequential Continuous Cohorts
}

Robert W Malone ( $\sim$ RWMaloneMD@gmail.com )

RW Malone MD LLC https://orcid.org/0000-0003-0340-7490

Kevin M Tomera

Beloit Health System, Department of Urology, Beloit, Wisconsin https://orcid.org/0000-0001-5991-1157

Leo Egbujiobi

Beloit Health System, Department of Cardiology, Beloit, Wisconsin

Joseph K Kittah

Beloit Health System, Department of Pulmonary \& Critical Care, Beloit, Wisconsin

\section{Research Article}

Keywords: COVID-19, cyclo-oxygenase inhibitors, famotidine, celecoxib, dexamethasone, glucocorticoid, SARS-CoV-2

Posted Date: May 17th, 2021

DOl: https://doi.org/10.21203/rs.3.rs-526394/v1

License: (9) This work is licensed under a Creative Commons Attribution 4.0 International License. Read Full License 


\section{Abstract}

We seek to rapidly identify, test and develop combinations of repurposed drugs to enable cost-effective treatments that reduce the risk of disease or death from SARS-CoV-2 infection. We hypothesize that the morbidity and mortality of COVID-19 reflects overactive host inflammatory responses to infection and is not principally due to the primary direct cellular, organ and tissue damage attributable to viral infection. Stepwise clinical development has identified the combination of High Dose (HD) famotidine and celecoxib (famcox) as a promising adjuvant anti-inflammatory protocol. We now report results from a retrospective observational comparative cohort study designed to provide an estimate of the potential benefits, risks, prognosis and diagnostic laboratory findings associated with administration of dexamethasone in addition to famcox for treatment of newly hospitalized COVID-19 disease in a community hospital setting. Study enrollment was restricted to patients at WHO 4-5. In the group receiving adjuvant treatment with famcox without dexamethasone (active control) there were no deaths during hospitalization $(0 / 18=0 \%$ mortality). A total of six deaths occurred in the group receiving famcox + dexamethasone $(6 / 21=29 \%$ mortality). There was a significant difference in mortality between the two groups, $X^{2}(1, N=43)=7.305, p<0.007$. Median time to event for reaching WHO score of $<4$ was 3.5 days in the control group (famcox (-) dex) versus 10 days for the experimental group (famcox (+) dex) $\mathrm{P}<$ 0.001 . We conclude that use of the potent non-specific anti-inflammatory corticosteroid dexamethasone in addition to the specific anti-inflammatory famcox protocol should only be considered in late stage COVID-19 disease in patients less than 70 years of age. The effects of added dexamethasone on laboratory biomarkers, and particularly on neutrophil count, lymphocyte count, and neutrophil to lymphocyte ratio raise concerns about the long-term effects of dexamethasone treatment with or without famcox during acute COVID-19 on the incidence and severity of chronic COVID ("Iong COVID" or PASC).

\section{Introduction}

Coronavirus Disease 2019 (COVID-19) develops in a subset of patients infected by the severe acute respiratory syndrome-coronavirus 2 (SARS-CoV-2). The estimated or measured incidence of COVID-19 disease in those with positive PCR tests for SARS-CoV-2 RNA varies. In some reports COVID-19 incidence may be as low as $20 \%$, but disease incidence is generally considered to be approximately $50 \%$ of infected patients (He et al., 2020; Hu et al., 2020; Ing et al., 2020; Long et al., 2020; Mizumoto et al., 2020; Tian et al., 2020). Of those that do not develop clinical COVID-19, approximately half of PCR positive asymptomatic patients eventually develop lung abnormalities which may be detected by computed tomography (Kronbichler et al., 2020). Therefore, SARS-CoV-2 infection is a necessary precursor, but infection alone does not predict either risk or severity of COVID-19 disease development.

Our overall objective is to rapidly identify, test and clinically develop combinations of repurposed drugs to enable cost-effective treatments that reduce the risk of disease or death from SARS-CoV-2 infection. We hypothesize that the morbidity and mortality of COVID-19 is largely driven by overactive host inflammatory responses to infection, and is not principally due to direct cellular, organ and tissue damage attributable to viral infection. This hypothesis is neither original nor unique to COVID-19; the predominant 
role of host inflammatory responses in other causes of acute respiratory distress syndrome pathophysiology is well documented (Wong et al., 2019). Rather than focusing on direct-acting antiviral drugs (a historically ineffective strategy for acute viral pneumonias (Ruuskanen et al., 2011)), we seek to identify and develop combinations of pharmaceutical agents with complementary mechanisms of action (MOA) that will mitigate the hyperinflammatory cascade triggered by SARS-CoV-2 infection. We propose that selection of pharmaceuticals which target more specific mechanistic pathways involved in COVID-19 inflammation will reduce off-target non-specific effects which may complicate clinical management, reduce efficacy and increase treatment emergent adverse events. The decades of experience in developing therapeutic drug cocktails for AIDS guides our strategy; optimal solutions typically require multiple drugs with complementary MOA.

In the United States during July 2020, public disclosure in the lay press followed by publication of preliminary results concerning the use of dexamethasone in hospitalized patients with COVID-19 (Recovery_Collaborative_Group et al., 2020) triggered a surge of dexamethasone treatment in all phases of hospitalized COVID-19 (including the President of the United States). Like many others during this period, hospitalists practicing in our community hospital setting (Beloit Memorial, Beloit, WI) began combining dexamethasone with other treatment regimens for hospitalized COVID-19, including the binary (HD) famotidine + celecoxib adjuvant protocol previously pioneered at this location (Tomera and Kittah, 2020; Tomera et al., 2020; 2021). This created an opportunity to retrospectively collect, analyze and compare clinical data and outcomes from continuous consecutive cohorts of patients receiving adjuvant therapy that targets specific mechanistic pathways (histamine H1R and COX-2 activities) with or without

the added effects of the non-specific, broad-spectrum anti-inflammatory dexamethasone (which does not have specific COVID-19 mechanistic pathways). Herein we report outcomes of treating consecutive cohorts of hospitalized COVID-19 patients using High Dose (HD) famotidine plus celecoxib (famcox) treatment without or with added dexamethasone.

\section{Study Purpose, Strengths and Limitations}

The purpose of this retrospective observational comparative cohort study is to provide an initial estimate of the potential benefits, risks, prognosis and diagnostic laboratory findings associated with administration of dexamethasone in addition to HD famotidine and celecoxib (famcox) for treatment of newly hospitalized COVID-19 disease in a community hospital setting. In this study, the HD famotidine+ celecoxib group serves as the (active) control for the HD famotidine + celecoxib + dexamethasone group. Addition of dexamethasone is the experimental variable. Study strengths include a) comparison of two continuous cohorts drawn sequentially from a single community hospital, b) the reported outcomes rely on objective rather than subjective measures, and c) multiple clinically significant objective outcome variables are analyzed and reported. A key weakness is that this study design is not able to control for all factors (known, unknown and unknowable) that differ between the two cohorts at the point of enrollment into the study, and so is subject to uncontrolled confounding during group selection. Reliance on a single hospital site and continuous accrual into each cohort based on date of admission may partially mitigate confounding due to selection bias. 


\section{Methods}

\section{Definitions of sample groups and primary outcome measures.}

The 25 patient active control group (HD famotidine + celecoxib) selected for this analysis has been previously summarized (Tomera et al., 2021). This group consists of a consecutive series of 25 cases of COVID-19 treated with the combination of HD famotidine + celecoxib (famcox) as adjuvant therapy to standard of care from the same hospital. From May 20, 2020 to August 5, 2020, all hospitalized patients (unless absolutely contraindicated) that were admitted to Beloit Memorial Hospital with a clinical diagnosis of COVID-19 as well as a positive RT-PCR test for SARS-CoV-2 received both HD famotidine $80 \mathrm{mg}$ oral four times a day (QID) and a celecoxib oral (PO) loading dose of $400 \mathrm{mg}$ followed by $200 \mathrm{mg}$ PO two times a day (BID) beginning within 24 hours of admission.

After the RECOVERY trial preliminary analysis publication concerning use of dexamethasone to treat COVID-19 (Recovery_Collaborative_Group et al., 2020) and changes in NIH guidelines, a second consecutive series of 25 cases of COVID-19 treated with dexamethasone and the combination of HD famotidine + celecoxib (famcox) as adjuvant therapy plus standard of care from the same hospital were identified and summarized. This series of cases serves as the experimental group for the analysis described herein. From August 21, 2020 to October 9, 2020, all hospitalized patients (unless absolutely contraindicated) that were admitted to Beloit Memorial Hospital with a clinical diagnosis of COVID-19 as well as a positive RT-PCR test for SARS-CoV-2 received dexamethasone intravenously (IV) either 4mg every 12 hours or $6 \mathrm{mg}$ daily with both HD famotidine $80 \mathrm{mg}$ oral (per os, or PO) four times a day (QID) and a celecoxib PO loading dose of $400 \mathrm{mg}$ followed by $200-400 \mathrm{mg}$ celecoxib PO two times a day (BID) beginning within 24 hours of admission.

From each group of 25 sequentially admitted patients, only those admitted with a WHO score of $\geq 4$ (8point scale, see Table 1) were selected for inclusion in the subsequent comparative study analyses. Primary outcome measures were pre-defined prior to analysis. Two primary outcome analyses were performed; 1 ) statistical analysis of time to event for achieving a WHO score of $\leq 3$ in each group (with correction for censoring due to death) and 2) comparative analysis of in hospital mortality (prior to discharge). No follow up outcomes were captured or analyzed after discharge from the hospital. For each patient, baseline and outcome laboratory test data as well as WHO category assessment on a daily basis during hospital course were extracted from hospital records and entered into an Excel spreadsheet by one of the investigators (KT). Exploratory outcomes consisted of comparative analysis of the following objective test data at entry into study and at discharge or death; a) D-dimer, b) eGFR (censoring for renal replacement therapy), c) Serum creatinine (censoring for renal replacement therapy), d) percent lymphocytes as a fraction of total white blood cells, e) absolute lymphocyte count, $f$ ) neutrophil to lymphocyte ratio, g) serum C-reactive protein, h) serum lactate dehydrogenase, i) serum ferritin, and j) serum aspartate aminotransferase.

This study has been conducted under approval of the Beloit Memorial Health system Institutional Review Board (IORG001171, file 20-05-1). 
Table 1

Eight point WHO ordinal scale for clinical improvement

\begin{tabular}{|llc|}
\hline Patient State & Descriptor & Score \\
\hline Uninfected & No clinical or virological evidence of infection & 0 \\
\hline Ambulatory & No limitation of activities & 1 \\
\cline { 2 - 3 } Hospitalized Mild Disease & Limitation of activities & 2 \\
\cline { 2 - 3 } & Hospitalized, no oxygen therapy & 3 \\
\hline Hospitalized Severe Disease & Oxygen by mask or nasal prongs & 4 \\
\cline { 2 - 3 } & Non-invasive ventilation or high-flow oxygen & 5 \\
\cline { 2 - 3 } & Intubation and mechanical ventilation & 6 \\
\hline & Ventilation + additional organ support (pressors, RRT, ECMO) & 7 \\
\hline Dead & Death & 8 \\
\hline
\end{tabular}

\section{Data analysis}

For both groups, patients were filtered for inclusion in study analyses based on WHO score at admission, with only those patients meeting study inclusion criteria of WHO score $\geq 4$ being included in subsequent analyses. Eighteen of the original twenty-five consecutive cases (72\%) in the control group (famcox without dexamethasone) met the analysis inclusion criteria, while twenty-one of the twenty-five consecutive cases (84\%) in the experimental group (famcox with dexamethasone) met inclusion criteria. Demographic characteristics, risk factor characteristics, and laboratory test characteristics at entry (baseline) were summarized for both groups. Statistical comparison of the distribution of these characteristics between the two groups were performed using the Stata v14.2 software package, and both test type (Mann-Whitney, Wilcox Signed Rank, t test (two arm), Fisher's exact, chi squared) and outcome of null hypothesis testing ( $P$ value) were summarized. Prior to comparative analysis, in the case of continuous data, each data group (control and experimental) was tested for normal distribution using a Shapiro-Wilk W test. Based on outcome, either parametric or non-parametric statistical tests were employed for grouped data comparisons of these baseline characteristics.

The primary time-to-event endpoint was graphically summarized as Kaplan-Meier curves for the two groups. Statistical comparison of curves was performed using both log-rank (Mantel-cox) and GehanBreslow-Wilcoxon testing with correction for censoring due to death during hospitalization using GraphPad Prism software v9.0.0 and the product-limit method. Hazard ratios were calculated using both methods. Null hypothesis test $P$ value (two tailed) reflects the null hypothesis that the Kaplan-Meir time to event curves are identical in the overall population. The statistical analysis of the mortality primary endpoint was performed using the Pearson's chi-squared test and the Stata v14.2 software package. 
Median time to event was defined as the time at which the Kaplan-Meir staircase survival curve crosses the $50 \%$ event rate.

Grouped or pair-matched (admission vs discharge) laboratory data were also statistically compared using Stata v14.2 and Microsoft Excel v16.14.1. Both software packages were used to calculate mean and median values for each group. Again, prior to selection of comparative statistical tests, each dataset was analyzed for normal distribution using a Shapiro-Wilk W test, and then the comparative statistical test type was selected based on whether data met criteria for normal distribution (parametric test if normally distributed, non-parametric if not) and whether the comparison involved matched pair or grouped data (Stata v14.2). Mean, median, standard deviation, P-value, specific test, and nature of comparison (grouped or paired data) were tabularized. Distribution, median, and standard deviations for each data set were graphically summarized as truncated violin plots using GraphPad Prism software v9.0.0.

Heatmap plots were used to graphically summarize individual laboratory data. Using Microsoft Excel (v2101) lab value sets corresponding to individual patients were sorted by WHO category at time of entry into the study (WHO 5 or 4), study entry versus discharge value differences were calculated, and \%change determined as ((discharge value - entry value)/(entry value) $\times 100 \%$. The $\%$ change values were then $\log _{10}$ transformed, with $0 \%$ change values coded as zero ("0"). To normalize the heat map so that all lab values were expressed as either positive (improved) or negative (deteriorated), corresponding sign values $(+/-)$ were assigned to each data point based on improvement or deterioration relative to baseline at study entry. Resulting data were grouped into related biomarker categories (inflammatory, hematologic, etc.) and plotted as heat maps using GraphPad Prism software v9.0.0.

\section{Baseline patient characteristics}

Table 2 summarizes the baseline demographics, clinical characteristics, and grouped laboratory values for the control (famcox (-) Dex) and experimental (famcox (+) Dex) treatment groups. At entry into the study, $73 \%$ of the control group met WHO criteria for mild hospitalized COVID requiring oxygen (WHO 4) and $27 \%$ met WHO criteria for severe hospitalized COVID (WHO 5). In contrast, $67 \%$ of the experimental group met WHO criteria for mild hospitalized COVID requiring oxygen (WHO 4) and 33\% met WHO criteria for severe hospitalized COVID (WHO 5). Fischer's exact test did not meet criteria for rejecting the null hypothesis of no difference between the two groups $(P=1.00)$. Mean age was $63.4 y$ (control) versus $64.5 y$ (experimental) (t-test, $P=0.76$ ). Gender distribution was also well balanced between the two groups (59\% male in control, $57 \%$ in experimental, $P=0.66$ ), as were the pre-existing risk factors of body mass index $(B M I ; P=0.81)$, obesity defined as $B M I>30(P=1.00)$, hypertension $(P=0.53)$, prior diagnosis of cardiovascular disease $(P=0.34)$, diabetes $(P=1.00)$, renal disease $(P=0.43)$, or asthma/COPD $(P=$ 0.43). Although overall ethnic distribution differences between the two groups did not meet statistical significance $(P=0.87)$; the control group overall included a larger proportion of black $(41 \%)$ and Hispanic (23\%) patients relative to the experimental group (5\% black, $10 \%$ Hispanic). No significant differences between the two groups were observed between baseline hematologic laboratory test values, 
inflammatory marker laboratory test values, serum D-dimer levels, renal function test values (eGFR and creatinine), and hepatic function laboratory test values. 
Table 2

Baseline demographics and clinical characteristics ${ }^{*}$

\begin{tabular}{|c|c|c|c|c|}
\hline Characteristic & $\begin{array}{l}\text { Famcox }(-) \\
\text { Dex }\end{array}$ & Famcox (+) Dex & $\begin{array}{l}\mathrm{P} \\
\text { value }\end{array}$ & $\begin{array}{l}\text { Statistical } \\
\text { Test }\end{array}$ \\
\hline \multicolumn{5}{|l|}{ WHO Scale - Baseline (Day 0) } \\
\hline$\%$ WHO Scale "4" & $73 \%$ & $67 \%$ & \multirow[t]{2}{*}{1.00} & \multirow[t]{2}{*}{ Fisher's exact } \\
\hline$\%$ WHO Scale " 5 " & $27 \%$ & $33 \%$ & & \\
\hline Age (years) & $63.4 y$ & $64.5 y$ & 0.76 & $\begin{array}{l}\text { t test (two } \\
\text { arm) }\end{array}$ \\
\hline Gender (M) & $59 \% \mathrm{M}$ & $57 \% \mathrm{M}$ & 0.66 & Fisher's exact \\
\hline Body Mass Index & $\begin{array}{l}35.1 ; 34.5 \\
(6.16)\end{array}$ & $35.5 ; 35.5(6.15)$ & 0.81 & $\begin{array}{l}\text { t test (two } \\
\text { arm) }\end{array}$ \\
\hline Obesity & $95 \%$ & $76 \%$ & 1.00 & Fisher's exact \\
\hline Hypertension & $73 \%$ & $86 \%$ & 0.53 & Fisher's exact \\
\hline Cardiovascular disease & $41 \%$ & $29 \%$ & 0.34 & Fisher's exact \\
\hline Diabetes & $45 \%$ & $43 \%$ & 1.00 & Fisher's exact \\
\hline Renal disease & $27 \%$ & $10 \%$ & 0.43 & Fisher's exact \\
\hline Asthma/COPD & $9 \%$ & $24 \%$ & 0.43 & Fisher's exact \\
\hline \multicolumn{5}{|l|}{ Ethnicity } \\
\hline White & $36 \%$ & $81 \%$ & \multirow[t]{4}{*}{0.87} & \multirow[t]{4}{*}{ Fisher's exact } \\
\hline Black & $41 \%$ & $5 \%$ & & \\
\hline Hispanic & $23 \%$ & $10 \%$ & & \\
\hline Native American & $0 \%$ & $5 \%$ & & \\
\hline \multicolumn{5}{|c|}{ Hematologic Laboratory tests- Baseline } \\
\hline \% Lymphocytes & $14.1 ; 12(7.7)$ & $13.1 ; 14(6.8)$ & 0.67 & $\begin{array}{l}\mathrm{t} \text { test (two } \\
\mathrm{arm})\end{array}$ \\
\hline Absolute Neutrophil Count & $7.2 ; 5.7(6.4)$ & $7.2 ; 6.6(4.7)$ & 0.74 & $\begin{array}{l}\text { Mann- } \\
\text { Whitney }\end{array}$ \\
\hline Absolute Lymphocyte Count & $0.8 ; 0.8(0.3)$ & $0.9 ; 0.8(0.5)$ & 0.66 & $\begin{array}{l}\text { Mann- } \\
\text { Whitney }\end{array}$ \\
\hline Neutrophil to Lymphocyte Ratio & $\begin{array}{l}10.9 ; 6.9 \\
(16.4)\end{array}$ & $9.8 ; 7.3(6.3)$ & 0.46 & $\begin{array}{l}\text { Mann- } \\
\text { Whitney }\end{array}$ \\
\hline
\end{tabular}

*Data presented as mean; median (SD) or numbers (\%) at study entry. 


\begin{tabular}{|c|c|c|c|c|}
\hline Characteristic & $\begin{array}{l}\text { Famcox (-) } \\
\text { Dex }\end{array}$ & Famcox (+) Dex & $\begin{array}{l}P \\
\text { value }\end{array}$ & $\begin{array}{l}\text { Statistical } \\
\text { Test }\end{array}$ \\
\hline \multicolumn{5}{|c|}{ Inflammatory Marker Laboratory tests- Baseline } \\
\hline Serum C-Reactive protein & $\begin{array}{l}10.8 ; 6.2 \\
(10.7)\end{array}$ & $12.4 ; 15.4(7.5)$ & 0.31 & $\begin{array}{l}\text { Mann- } \\
\text { Whitney }\end{array}$ \\
\hline Serum Lactate Dehydrogenase & $318 ; 307(110)$ & $571 ; 382(695)$ & 0.06 & $\begin{array}{l}\text { Mann- } \\
\text { Whitney }\end{array}$ \\
\hline Serum Ferritin & $665 ; 488(807)$ & $1066 ; 499$ (1770) & 0.47 & $\begin{array}{l}\text { Mann- } \\
\text { Whitney }\end{array}$ \\
\hline \multicolumn{5}{|c|}{ Coagulopathy Laboratory test- Baseline } \\
\hline Serum D-dimer & $\begin{array}{l}2.02 ; 0.89 \\
(3.33)\end{array}$ & $1.68 ; 1.09$ (1.99) & 0.58 & $\begin{array}{l}\text { Mann- } \\
\text { Whitney }\end{array}$ \\
\hline \multicolumn{5}{|c|}{ Renal Function Laboratory tests- Baseline } \\
\hline $\begin{array}{l}\text { Glomerular Filtration Rate } \\
\text { (estimated) }\end{array}$ & $71.5 ; 62(36.4)$ & $70.5 ; 73(29.3)$ & 0.49 & $\begin{array}{l}\mathrm{t} \text { test (two } \\
\text { arm) }\end{array}$ \\
\hline Serum Creatinine & $\begin{array}{l}1.21 ; 1.09 \\
(0.59)\end{array}$ & $1.20 ; 1.0(0.34)$ & 0.46 & $\begin{array}{l}\text { Mann- } \\
\text { Whitney }\end{array}$ \\
\hline \multicolumn{5}{|c|}{ Hepatic Function Laboratory tests- Baseline } \\
\hline Aspartate Aminotransferase & $52.6 ; 47(24.7)$ & $\begin{array}{l}\text { 104.8; } 54.5 \\
(132.3)\end{array}$ & 0.29 & $\begin{array}{l}\text { Mann- } \\
\text { Whitney }\end{array}$ \\
\hline Total Bilirubin & $1.2 ; 0.8(1.7)$ & $0.95 ; 0.9(0.46)$ & 0.57 & $\begin{array}{l}\text { Mann- } \\
\text { Whitney }\end{array}$ \\
\hline
\end{tabular}

\section{Results}

\section{Time to event analysis.}

The time to event for progression to WHO category 3 or less $(\mathrm{WHO}<4)$ for control (famcox $(-)$ dex; black line) and treatment (famcox (+) dex; red line) groups are summarized in Fig. 1 as Kaplan-Meir staircase curves. Curve comparison using Log-rank (Mantel-Cox) test yields a chi squared value of 20.19, P value of $<0.0001$, and supports the conclusion that the two curves are significantly different. Similarly, curve comparison using the Gehan-Breslow-Wilcoxon test yields a chi squared value of 21.46, P value of < 0.0001 , and also supports the conclusion that the two curves are significantly different. Median time to event for reaching WHO score of $<4$ was 3.5 days in the control group (famcox - dex) versus 10 days for the experimental group (famcox + dex). Hazard Ratio (Mantel-Haenszel) for the treatment group (+ dex) relative to control group (- dex) was 7.23 (95\% confidence interval of 3.05 to 17.14). Hazard Ratio (log 
rank) for the treatment group relative to the control group was 3.43 (95\% confidence interval of 1.64 to 7.17).

\section{Mortality analysis.}

Cumulative mortality during hospitalization in the two treatment groups was analyzed. In the group receiving adjuvant treatment with $\mathrm{HD}$ famotidine + celecoxib (without added dexamethasone), all enrolled patients were successfully discharged; there were no deaths during hospitalization $(0 / 18=0 \%$ mortality). A total of six deaths were recorded during hospitalization in the group receiving HD famotidine + celecoxib + dexamethasone $(6 / 21=29 \%$ mortality). Of these deaths, four had been admitted and enrolled at WHO grade 5, and two admitted and enrolled at WHO grade 4. Of those enrolled at WHO grade 4, death occurred at days 18 and 20 post enrollment. For those enrolled at WHO grade 5, death occurred at days 9 , 11,12 , and 17. Chi squared comparison of these outcomes was performed, with $2 \times 2$ table comparison of outcome (discharged or deceased) and treatment group ((-) or (+) dexamethasone (Stata v14.2). Results demonstrate that there was a significant difference in mortality between the two groups, $X^{2}(1, N$ $=43)=7.305, p<0.007$.

\section{Comparison of Oxygen usage over time.}

Oxygen usage, and the technology employed to administer oxygen, is one of the most straightforward and objective measures of clinical status for COVID-19, a disease with a strong component of compromised gas exchange influencing clinical outcomes. As demonstrated by Table 1, oxygen usage plays a major role in the initial eight-point WHO scale (or nine, if you include grade zero). Figure 2 provides a simple plot of oxygen usage for enrolled patients over time, with censoring of those patients that became intubated and/or died. Only the group treated with HD famotidine + celecoxib + dexamethasone included patients that progressed to requiring intubation or death (ergo, WHO grade 6, 7 or 8). No patients in either group were initially enrolled at WHO grade 6 or 7.

\section{Comparison of C-reactive protein levels over time.}

C-Reactive Protein (CRP) is both an acute inflammatory phase marker and an important prognostic marker for poor outcomes in acute respiratory distress syndrome (Ridker et al., 2008; Sharma et al., 2016), when elevations are sustained reflects a persistent state of inflammation (Bajwa et al., 2009), and is also a prognostic marker for COVID-19 (Potempa et al., 2020). Particularly when considered in the context of oxygen usage as a function to time, CRP provides an excellent moving summary of the overall status of pulmonary inflammation and compromised gas exchange in COVID-19 patients. In Fig. 3, changes in CRP over time are graphically summarized for each patient enrolled in the two comparison groups of this study; the famcox (-) dex group are plotted in black, and famcox (+) dex plotted in red.

\section{Biomarker analysis; enrollment and discharge}


As described above in the methods section, laboratory biomarker test results were collected for each enrolled patient at study entry and as close to study exit (discharge or death) as available. For purpose of this report, these results were clustered as 1 ) inflammatory biomarkers analyzed included CRP, Lactate Dehydrogenase (LDH), and ferritin. 2) Primary hematologic biomarkers included lymphocyte fraction of total white blood cells, absolute neutrophil count, and absolute lymphocyte count. In addition, the derived parameter of (absolute) neutrophil count to (absolute) lymphocyte count ratio (neutrophil to lymphocyte ratio or NLR) was also calculated and analyzed. 3) The coagulation marker chosen for this analysis was the D-dimer values for each patient at admission to the study and at exit (discharge or death). 4) Renal function biomarkers selected for evaluation included estimated glomerular filtration rate (eGFR) and serum total creatinine levels (creatinine). 5) Hepatic damage biomarkers similarly evaluated include aspartate aminotransferase (AST) and total (direct and indirect) serum bilirubin.

\section{Inflammatory Biomarkers.}

Figure 4 summarizes CRP (panel A), LDH (Panel B), and ferritin (Panel C) analyses. The diagnostic and prognostic value of CRP for COVID is discussed above. An increase of LDH reflects tissue/cell damage. Serum LDH is recognized as an important surrogate biomarker for the activity and severity of the chronic lung diseases known as idiopathic pulmonary fibrosis and severe pulmonary interstitial disease (Kishaba et al., 2014). Serum ferritin is an acute phase reactant. Ferritin concentration on admission is an independent risk factor for disease severity in COVID-19 patients (Lin et al., 2020). In the cohort treated

with HD famotidine + celecoxib (famcox without dexamethasone) as adjuvant therapy, grouped pairwise analysis of all three inflammatory biomarkers show statistically significant improvement between enrollment and discharge (Table 3a). In the cohort treated with both famcox and dexamethasone, grouped pairwise analysis of all three inflammatory biomarkers failed to demonstrate statistically significant changes between enrollment and discharge (or death). In addition to pairwise comparison of results over time within treatment group, results were compared between treatment cohorts at enrollment (Day 0 ) and separately at discharge or death (Table $3 \mathrm{~b}$ ). This comparison is designed to detect statistically significant differences between treatment groups in laboratory test findings between the treatment cohorts at time of entry and exit from the study (of necessity using grouped rather than paired data comparisons). In general, for a given sample size, the statistical power of either parametric or nonparametric statistical tests to detect differences between grouped data sets is less than for paired data sets. In the case of the inflammatory biomarker data, the only data comparison reaching statistical significance $(p<0.05)$ at study exit was serum LDH. The LDH data comparison across treatment groups was close to meeting criteria for statistical significance between the two cohorts at entry into the study, and so this statistical difference should be interpreted conservatively.

\section{Table 3: Summary of inflammatory biomarker statistical analyses and findings}




\begin{tabular}{|c|c|c|c|c|c|c|c|}
\hline \multicolumn{8}{|c|}{ 3a: Intra-Treatment Group Analyses } \\
\hline $\begin{array}{c}\text { Dexamethasone } \\
\text { addition }\end{array}$ & Event & Mean & Median & SD & $\begin{array}{c}\mathrm{P} \\
\text { value }\end{array}$ & Test & $\begin{array}{c}\text { Data Set } \\
\text { Characteristics }\end{array}$ \\
\hline \multicolumn{8}{|c|}{ Serum C-reactive protein (CRP) } \\
\hline$(-)$ & Day 0 & 10.8 & 6.2 & 10.7 & \multirow[t]{2}{*}{0.0036} & Wilcox & \multirow[t]{2}{*}{ Paired } \\
\hline$(-)$ & Discharge & 4.4 & 3.3 & 4.6 & & $\begin{array}{l}\text { Signed } \\
\text { Rank }\end{array}$ & \\
\hline$(+)$ & Day 0 & 11.7 & 14.9 & 7.5 & \multirow[t]{2}{*}{0.305} & Wilcox & \multirow[t]{2}{*}{ Paired } \\
\hline$(+)$ & Discharge & 7.8 & 2.6 & 9.8 & & Rank & \\
\hline \multicolumn{8}{|c|}{ Serum Lactate dehydrogenase (LDH) } \\
\hline$(-)$ & Day 0 & 318.6 & 307 & 109.7 & \multirow[t]{2}{*}{0.0003} & Wilcox & \multirow[t]{2}{*}{ Paired } \\
\hline$(-)$ & Discharge & 265.1 & 241.5 & 81.1 & & $\begin{array}{l}\text { Signed } \\
\text { Rank }\end{array}$ & \\
\hline$(+)$ & Day 0 & 571.3 & 382 & 695.8 & \multirow[t]{2}{*}{0.140} & Wilcox & \multirow[t]{2}{*}{ Paired } \\
\hline$(+)$ & Discharge & 446.1 & 299 & 428.4 & & $\begin{array}{l}\text { Signed } \\
\text { Rank }\end{array}$ & \\
\hline \multicolumn{8}{|c|}{ Serum Ferritin } \\
\hline$(-)$ & Day 0 & 664.8 & 488 & 807.3 & \multirow[t]{2}{*}{0.0033} & Wilcox & \multirow[t]{2}{*}{ Paired } \\
\hline$(-)$ & Discharge & 412.1 & 304 & 407.8 & & $\begin{array}{l}\text { Signeu } \\
\text { Rank }\end{array}$ & \\
\hline$(+)$ & Day 0 & 1066.3 & 499 & 1770.1 & \multirow[t]{2}{*}{0.122} & Wilcox & \multirow[t]{2}{*}{ Paired } \\
\hline$(+)$ & Discharge & 578.1 & 505 & 484.8 & & $\begin{array}{l}\text { Signed } \\
\text { Rank }\end{array}$ & \\
\hline
\end{tabular}

\begin{tabular}{|c|c|c|c|c|}
\hline \multicolumn{5}{|c|}{ 3b: Inter-Treatment Group Analyses } \\
\hline $\begin{array}{l}\text { Dexamethasone } \\
\text { addition }\end{array}$ & Event & P value & Test & Data Set Characteristics \\
\hline \multicolumn{5}{|c|}{ Serum C-reactive protein (CRP) } \\
\hline$(-)$ & Day 0 & 0.53 & Mann-Whitney & Grouped \\
\hline$(+)$ & Day 0 & & & \\
\hline$(-)$ & Discharge & 0.62 & Mann-Whitney & Grouped \\
\hline$(+)$ & Discharge & & & \\
\hline \multicolumn{5}{|c|}{ Serum Lactate dehydrogenase (LDH) } \\
\hline$(-)$ & Day 0 & 0.06 & Mann-Whitney & Grouped \\
\hline$(+)$ & Day 0 & & & \\
\hline$(-)$ & Discharge & 0.03 & Mann-Whitney & Grouped \\
\hline$(+)$ & Discharge & & & \\
\hline \multicolumn{5}{|c|}{ Serum Ferritin } \\
\hline$(-)$ & Day 0 & 0.47 & Mann-Whitney & Grouped \\
\hline$(+)$ & Day 0 & & & \\
\hline$(-)$ & Discharge & 0.25 & Mann-Whitney & Grouped \\
\hline
\end{tabular}

\section{Hematologic Biomarkers.}

Figure 5 summarizes hematologic biomarker data at the time of study entry (Day 0 ) and exit (Discharge) for each treatment cohort (famcox (-) dexamethasone, famcox (+) dexamethasone). Hematologic biomarkers compared include the lymphocyte fraction of the total white blood cell automated count (Panel A: Lymphocytes, \% WBC), the absolute neutrophil count (Panel B: ANC/microliter), absolute lymphocyte count (Panel C: Lymphocytes $\times 10^{3} /$ microliter), and the absolute neutrophil count to absolute lymphocyte ratio (Panel D: $\log _{10}$ NLR). Lymphopenia is commonly observed in patients with COVID-19 symptoms and may be associated with both disease severity and mortality (Chan et al., 2020). At Beloit Memorial Hospital, the normal range for the lymphocyte fraction as a percentage of white blood cells is 
defined as $30-50 \%$. Absolute lymphocyte count normal range in this hospital laboratory is $1.0 \mathrm{x}$ $10^{3} /$ microliter (low) to $4.8 \times 10^{3} /$ microliter (high). Elevated levels of peripheral blood neutrophils are also associated with increased risk of progression to more severe COVID-19 (Elshazli et al., 2020). Absolute neutrophil count normal range in this laboratory is $2.4 \times 10^{3} /$ microliter (low) to $8.1 \times 10^{3} /$ microliter (high), with the lower bound for critical neutropenia of $<0.5 \times 10^{3} / \mathrm{microliter}$. Multiple studies have demonstrated that the absolute neutrophil to lymphocyte ratio is a predictor of COVID-19 outcomes in hospitalized patients (Qin et al., 2020). A neutrophil/lymphocyte ratio of $>6$ is characteristic of severe COVID-19 (Gottlieb et al., 2020). The neutrophil to lymphocyte ratio is plotted as $\log _{10}$ data to compensate for outlier values which distorted the overall violin plot, resulting in difficulty in comparing the distribution of the data values for each group. Results of comparative statistical analysis of the treatment groups are summarized in Table 4a and Table 4b.

As shown in Table 4a, statistical comparison of hematologic biomarkers within the famcox (-) dexamethasone adjuvant treatment group at study entry and exit consistently demonstrates significant $(P<0.05)$ improvement in paired laboratory results. In contrast, in all cases, analysis of hematologic biomarker laboratory responses in the famcox $(+)$ dexamethasone group fails to demonstrate statistically significant improvement in these parameters during the enrollment period. Noting the caveats discussed previously concerning statistical power when comparing grouped (rather than paired) data, as shown in Table $4 \mathrm{~b}$ no significant differences in the analyzed hematologic biomarkers were detected between the (-) and $(+)$ dexamethasone cohorts at time of enrollment. Surprisingly, despite the statistical power limitations of comparing grouped data sets, lymphocyte fraction comparison $(P=0.0005)$, absolute neutrophil count comparison $(P=0.0001)$, and the neutrophil and lymphocyte ratio $(P=0.0019)$ all met criteria for statistically significant improvement at study exit in the famcox (-) dexamethasone group compared to the $(+)$ dexamethasone cohort. In contrast, comparative analysis of absolute lymphocyte count $(P=0.49)$ did not meet criteria for significant differences between the treatment groups at study exit, suggesting that addition of dexamethasone to famcox adversely impacted the peripheral blood neutrophil to lymphocyte ratio predominantly due to impact on the peripheral blood neutrophil compartment.

\section{Table 4: Summary of hematologic biomarker statistical analyses and findings}


4a: Intra-Treatment Group Analyses

\begin{tabular}{|c|c|c|c|c|c|c|c|}
\hline $\begin{array}{l}\text { Dexamethasone } \\
\text { addition }\end{array}$ & Event & Mean & Median & SD & $\begin{array}{c}\mathrm{P} \\
\text { value }\end{array}$ & Test & $\begin{array}{c}\text { Data Set } \\
\text { Characteristics }\end{array}$ \\
\hline \multicolumn{8}{|c|}{ Lymphocyte Fraction (\% total white blood count) } \\
\hline$(-)$ & Day 0 & 14.06 & 12 & 7.7 & \multirow[t]{2}{*}{0.0009} & \multirow{2}{*}{$\begin{array}{c}\mathrm{t} \text { Test } \\
(2 \text { tailed })\end{array}$} & \multirow[t]{2}{*}{ Paired } \\
\hline$(-)$ & Discharge & 21.09 & 19 & 9.7 & & & \\
\hline$(+)$ & Day 0 & 13.10 & 14 & 6.8 & \multirow[t]{2}{*}{0.398} & \multirow{2}{*}{$\begin{array}{c}\text { t Test } \\
\text { (2 tailed) }\end{array}$} & \multirow[t]{2}{*}{ Paired } \\
\hline$(+)$ & Discharge & 11.70 & 12 & 6.2 & & & \\
\hline \multicolumn{8}{|c|}{ Absolute Neutrophil Count (ANC) } \\
\hline$(-)$ & Day 0 & 7.21 & 5.7 & 6.4 & \multirow[t]{2}{*}{0.0058} & Wilcox & \multirow[t]{2}{*}{ Paired } \\
\hline$(-)$ & Discharge & 4.24 & 3.9 & 1.4 & & $\begin{array}{l}\text { Slgned } \\
\text { Rank }\end{array}$ & \\
\hline$(+)$ & Day 0 & 7.18 & 6.6 & 4.7 & \multirow[t]{2}{*}{0.357} & Wilcox & \multirow[t]{2}{*}{ Paired } \\
\hline$(+)$ & Discharge & 7.93 & 8.0 & 3.4 & & $\begin{array}{l}\text { Signed } \\
\text { Rank }\end{array}$ & \\
\hline \multicolumn{8}{|c|}{ Absolute Lymphocyte Count (ALC) } \\
\hline$(-)$ & Day 0 & 0.79 & 0.8 & 0.34 & \multirow[t]{2}{*}{0.0020} & t Test & \multirow[t]{2}{*}{ Paired } \\
\hline$(-)$ & Discharge & 1.20 & 1.15 & 0.44 & & & \\
\hline$(+)$ & Day 0 & 0.91 & 0.8 & 0.51 & \multirow[t]{2}{*}{0.175} & Wilcox & \multirow[t]{2}{*}{ Paired } \\
\hline$(+)$ & Discharge & 1.18 & 1.00 & 0.75 & & $\begin{array}{c}\text { Signed } \\
\text { Rank }\end{array}$ & \\
\hline \multirow{2}{*}{\multicolumn{8}{|c|}{ Neutrophil to Lymphocyte Ratio (NLR) }} \\
\hline$(-)$ & Day 0 & & & & & Wilcox & \multirow[t]{2}{*}{ Paired } \\
\hline$(-)$ & Discharge & 5.2 & 3.8 & 6.5 & 0.0015 & $\begin{array}{l}\text { Slgned } \\
\text { Rank }\end{array}$ & \\
\hline$(+)$ & Day 0 & 9.8 & 7.3 & 6.3 & \multirow[t]{2}{*}{0.47} & Wilcox & \multirow[t]{2}{*}{ Paired } \\
\hline$(+)$ & Discharge & 8.6 & 7.0 & 5.1 & & Rank & \\
\hline
\end{tabular}

\begin{tabular}{|c|c|c|c|c|}
\hline \multicolumn{5}{|c|}{ 4b: Inter-Treatment Group Analyses } \\
\hline $\begin{array}{l}\text { Dexamethasone } \\
\text { addition }\end{array}$ & Event & $\mathrm{P}$ value & Test & Data Set Characteristics \\
\hline \multicolumn{5}{|c|}{ Lymphocyte Fraction (\% total white blood count) } \\
\hline$(-)$ & Day 0 & \multirow[t]{2}{*}{0.67} & t Test & \multirow[t]{2}{*}{ Grouped } \\
\hline$(-)$ & Day 0 & & (2 tailed) & \\
\hline$(+)$ & Discharge & \multirow[t]{2}{*}{0.0005} & t Test & \multirow[t]{2}{*}{ Grouped } \\
\hline$(+)$ & Discharge & & (2 tailed) & \\
\hline \multicolumn{5}{|c|}{ Absolute Neutrophil Count (ANC) } \\
\hline$(-)$ & Day 0 & \multirow[t]{2}{*}{0.74} & Mann-Whitney & \multirow[t]{2}{*}{ Grouped } \\
\hline$(+)$ & Day 0 & & & \\
\hline$(-)$ & Discharge & \multirow[t]{2}{*}{0.0001} & t Test & \multirow[t]{2}{*}{ Grouped } \\
\hline$(+)$ & Discharge & & (2 tailed) & \\
\hline \multicolumn{5}{|c|}{ Absolute Lymphocyte Count (ALC) } \\
\hline$(-)$ & Day 0 & 0.66 & Mann-Whitney & Grouped \\
\hline$(+)$ & Day 0 & \multirow{3}{*}{0.49} & \multirow{3}{*}{ Mann-Whitney } & \multirow{3}{*}{ Grouped } \\
\hline$(-)$ & Discharge & & & \\
\hline$(+)$ & Discharge & & & \\
\hline \multicolumn{5}{|c|}{ Neutrophil to Lymphocyte Ratio (NLR) } \\
\hline$(-)$ & Day 0 & \multirow[t]{2}{*}{0.50} & Mann-Whitney & \multirow[t]{2}{*}{ Grouped } \\
\hline$(+)$ & Day 0 & & & \\
\hline$(-)$ & Discharge & \multirow[t]{2}{*}{0.0019} & \multirow{2}{*}{ Mann-Whitney } & \multirow[t]{2}{*}{ Grouped } \\
\hline$(+)$ & Discharge & & & \\
\hline
\end{tabular}




\section{Coagulopathy biomarker.}

Coagulopathy is frequently reported in COVID-19 (Huang et al., 2020), and deep venous thrombosis and other pathologic coagulation events were present on admission in a subset of these patients. Figure 6 provides a graphical summary of the differences in D-dimer responses to famcox without (-) or with (+) co-administration of dexamethasone. D-dimer is a marker of fibrinolysis, and elevated D-dimer is a poor prognostic factor for COVID-19 (Tang et al., 2020a; Zhang et al., 2020; Zhou et al., 2020). Plasma D-dimer analysis is typically used for diagnosis of acute pulmonary embolism, deep vein thrombosis, intravascular coagulation and fibrinolysis, also disseminated intravascular coagulation. D-dimer levels < 1.56 have been associated with survival from hospitalized COVID-19, with levels $>1.56$ favoring mortality (Wendel Garcia et al., 2020). At the clinical testing laboratory employed for this study, a D-dimer level of < $0.5 \mathrm{mg} / \mathrm{L}$ fibrinogen-equivalent units (FEU) is considered within normal range, and $>1 \mathrm{mg} / \mathrm{L} \mathrm{FEU} \mathrm{is}$ considered critical. A summary of results from statistical comparison of the two treatment cohorts is provided in Table 5. Similar to all of the other biomarker evaluations, as summarized in Table 5a, statistical analysis of the cohort that was adjuvant treated with famcox but without dexamethasone demonstrated a significant improvement in $\mathrm{D}$-dimer laboratory values during the enrollment period $(\mathrm{P}=$ 0.0011). In contrast, with addition of dexamethasone this significant improvement was not observed $(P=$ 0.687). Table $5 \mathrm{~b}$ summarizes grouped data comparison between the treatment cohorts. No significant difference was observed in D-dimer levels at entry into the study. At exit from the analysis, D-dimer values for the two sets of grouped data did meet statistical criteria for significant difference $(P=0.019)$.

Table 5: Summary of coagulopathy biomarker statistical analyses and findings

\begin{tabular}{|c|c|c|c|c|c|c|c|}
\hline \multicolumn{8}{|c|}{ 5a: Intra-Treatment Group Analyses } \\
\hline $\begin{array}{c}\text { Dexamethasone } \\
\text { addition }\end{array}$ & Event & Mean & Median & SD & $\begin{array}{c}\mathrm{P} \\
\text { value }\end{array}$ & Test & $\begin{array}{c}\text { Data Set } \\
\text { Characteristics }\end{array}$ \\
\hline \multicolumn{8}{|c|}{ D-dimer values (fibrinogen-equivalent units) } \\
\hline$(-)$ & Day 0 & 2.02 & 0.88 & 3.33 & \multirow[t]{2}{*}{0.0011} & Wilcox & \multirow[t]{2}{*}{ Paired } \\
\hline$(-)$ & Discharge & 1.34 & 0.57 & 2.34 & & Rank & \\
\hline$(+)$ & Day 0 & 1.69 & 1.09 & 1.99 & \multirow[t]{2}{*}{0.687} & Wilcox & \multirow[t]{2}{*}{ Paired } \\
\hline$(+)$ & Discharge & 2.27 & 1.2 & 3.63 & & Rank & \\
\hline
\end{tabular}

\begin{tabular}{|c|c|c|c|c|c|}
\hline \multicolumn{7}{|c|}{ 5b: Inter-Treatment Group Analyses } \\
\hline $\begin{array}{c}\text { Dexamethasone } \\
\text { addition }\end{array}$ & Event & P value & Test & Data Set Characteristics \\
\hline \multicolumn{5}{|c|}{ D-dimer values (fibrinogen-equivalent units) } \\
\hline$(-)$ & Day 0 & 0.59 & Mann-Whitney & Grouped \\
\hline$(-)$ & Day 0 & & & Grouped \\
\hline$(+)$ & Discharge & 0.019 & Mann-Whitney & \\
\hline$(+)$ & Discharge & & & \\
\hline
\end{tabular}

\section{Renal function biomarkers.}


Based on prior COVID literature and clinical experience, estimated glomerular filtration rate and total serum creatine were selected as biomarkers for comparing the effects of famcox adjuvant treatment (with or without dexamethasone) on renal function. The estimated glomerular filtration rate (eGFR) for this comparison was calculated using the CKD-EPi equation and when applicable the African American correction was implemented. In this hospital, GFR $>90 \mathrm{~mL} / \mathrm{min} / 1.73$ sq meters is considered within the normal range. Serum creatinine measurements are a key diagnostic biomarker employed in assessing acute kidney injury (AKI) (Kellum et al., 2013); criteria for the syndrome are met if there is an increase in serum creatinine by $\geq 0.3 \mathrm{mg} / \mathrm{dL}$ within 48 hours, or an increase in serum creatinine to $\geq 1.5$ times baseline within the prior 7 days. In these cohorts, none of the patients treated with famcox (-) dex met criteria for AKI. Two of the patients (10\%) within the group treated with famcox (+) dex did develop AKI and were placed on renal replacement therapy. For purposes of summary graphing (Fig. 7) and statistical comparisons (Table 6), renal function biomarker data from these two patients were not included and were considered as censored.

Absent dexamethasone co-administration, the famcox cohort met statistical test criteria for significant improvement in both eGFR $(P=0.003)$ and serum creatinine level improvement $(P=0.036)$ (Table 6a) with a median eGFR improvement of $25 \mathrm{ml} / \mathrm{min} / 1.73$ sq meters. In contrast, the famcox cohort treated with dexamethasone did not meet statistical test criteria for improvement of either renal function biomarker. When comparing the two cohorts, no statistically significant difference was observed at entry. $10 \%$ of the patients on dexamethasone required dialysis and were censored for the statistical comparison analysis (Table $6 \mathrm{~b}$ ), further reducing the sample size for the $(+)$ dexamethasone cohort and increasing the imbalance between the groups for the renal function bioanalysis comparisons.

\section{Table 6: Summary of renal function biomarker statistical analyses and findings}

\begin{tabular}{|c|c|c|c|c|c|c|c|}
\hline \multicolumn{8}{|c|}{ 6a: Intra-Treatment Group Analyses } \\
\hline $\begin{array}{c}\text { Dexamethasone } \\
\text { addition }\end{array}$ & Event & Mean & Median & SD & $\begin{array}{c}\mathrm{P} \\
\text { value }\end{array}$ & Test & $\begin{array}{c}\text { Data Set } \\
\text { Characteristics } \\
\end{array}$ \\
\hline \multicolumn{8}{|c|}{ Estimated Glomerular Filtration Rate (GFR) $\left(\mathrm{mL} / \mathrm{min} / 1.73 \mathrm{~m}^{2}\right)$} \\
\hline$(-)$ & Day 0 & 71.5 & 62 & 36.4 & \multirow[t]{2}{*}{0.003} & t Test & \multirow[t]{2}{*}{ Paired } \\
\hline$(-)$ & Discharge & 92.5 & 89 & 39.7 & & & \\
\hline$(+)$ & Day 0 & 70.5 & 73 & 29.3 & \multirow[t]{2}{*}{0.485} & t Test & \multirow[t]{2}{*}{ Paired } \\
\hline$(+)$ & Discharge & 79.2 & 74 & 38.2 & & $(20$ & \\
\hline \multicolumn{8}{|c|}{ Serum Creatinine Levels (mg/ml) } \\
\hline$(-)$ & Day 0 & 1.21 & 1.09 & 0.59 & \multirow{2}{*}{0.036} & Wilcox & \multirow{2}{*}{ Paired } \\
\hline$(-)$ & Discharge & 0.99 & 0.9 & 0.59 & & $\begin{array}{l}\text { Signed } \\
\text { Rank }\end{array}$ & \\
\hline$(+)$ & Day 0 & 1.20 & 1.0 & 0.34 & \multirow[t]{2}{*}{0.455} & Wilcox & \multirow[t]{2}{*}{ Paired } \\
\hline$(+)$ & Discharge & 1.05 & 0.9 & 0.59 & & $\begin{array}{l}\text { Signied } \\
\text { Rank }\end{array}$ & \\
\hline
\end{tabular}




\begin{tabular}{|c|c|c|c|c|}
\hline \multicolumn{5}{|c|}{ 6b: Inter-Treatment Group Analyses } \\
\hline $\begin{array}{l}\text { Dexamethasone } \\
\text { addition }\end{array}$ & Event & $\mathrm{P}$ value & Test & Data Set Characteristics \\
\hline \multicolumn{5}{|c|}{ Estimated Glomerular Filtration Rate $(\mathrm{GFR})\left(\mathrm{mL} / \mathrm{min} / 1.73 \mathrm{~m}^{2}\right)$} \\
\hline$(-)$ & Day 0 & 0.92 & t Test & Grouped \\
\hline$(-)$ & Day 0 & & (2 tailed) & \\
\hline$(+)$ & Discharge & 0.28 & t Test & Grouped \\
\hline$(+)$ & Discharge & & (2 tailed) & \\
\hline \multicolumn{5}{|c|}{ Serum Creatinine Levels (mg/ml) } \\
\hline$(-)$ & Day 0 & 0.47 & Mann-Whitney & Grouped \\
\hline$(+)$ & Day 0 & & & \\
\hline$(-)$ & Discharge & 0.75 & Mann-Whitney & Grouped \\
\hline$(+)$ & Disc & & & \\
\hline
\end{tabular}

\section{Hepatic damage biomarkers.}

Elevated liver enzymes have been associated with COVID-19 treatment protocols, including those employing antifungal drugs, antibiotics, antivirals, and systemic corticosteroids (Lei et al., 2020). For high-level comparison of hepatic function for the famcox (-) dexamethasone and famcox (+) dexamethasone cohorts, aspartate aminotransferase (AST) and total (direct and indirect) serum bilirubin were selected for analysis.

AST is present in both the cytoplasm and mitochondria of liver, heart, skeletal muscle, and kidney cells, and is released into the circulatory compartment after damage of any of these organs. Elevated serum AST is observed after myocardial infarction, acute liver cell damage, and viral hepatitis among other conditions. In the case of COVID-19 (in contrast to most causes of hepatitis), AST levels are highly correlated with mortality relative to other liver injury markers (Lei et al., 2020). In this hospital, the upper boundary of the normal to high range for serum AST is 41 units/L.

Bilirubin, a metabolized byproduct of red cell hemolysis, is typically used as a biomarker for hepatic blood filtration and secretory function. Elevated total bilirubin can be an indirect indicator of direct hepatic damage, or of either micro or macro biliary tree blockage. In the context of COVID-19, elevated total bilirubin levels have been associated with antifungal, antiviral, and systemic corticosteroid administration (Lei et al., 2020).

Figure 8 provides a graphical summary of AST (Panel 8a) and total bilirubin levels (Panel 8b) at the time of entry into the study (Day 0 ) and at study exit (Discharge). For purpose of maintaining a legible linear violin plot which allows the range and distribution of values to be assessed, both summaries employ $\log 10$ transformation prior to plotting due to scale distortion due to outlier values. Table 7 provides a summary of serum AST and total bilirubin results obtained by statistical comparison of the two treatment cohorts, with 7a summarizing intra-cohort comparisons and 7b summarizing inter-cohort comparisons. As with all other analyzed biomarkers, there were statistically significant improvements in both AST ( $P=$ $0.0024)$ and bilirubin $(P=0.0080)$ levels during the enrollment period for the cohort treated with famcox $(-)$ dexamethasone as adjuvant therapy (Table 7a). In contrast, adjuvant treatment with famcox (+) 
dexamethasone as adjuvant therapy did not result in significant improvement of either marker during the study. Inter-treatment group analyses (Table 7b) did not detect statistically significant differences in either AST or bilirubin levels between the two cohorts at study entry. At exit from the study, no statistical difference between the cohorts was detected for AST levels, but a statistically significant difference $(P=$ 0.0012 ) was observed between the groups at exit for bilirubin, with mean and median levels of 0.69 and $0.6 \mathrm{mg} / \mathrm{dL}$ (respectively) in the cohort not treated with dexamethasone and mean and median levels of 1.21 and $0.8 \mathrm{mg} / \mathrm{dL}$ (respectively) in the cohort treated with dexamethasone.

Table 7: Summary of hepatic damage biomarker statistical analyses and findings

\begin{tabular}{|c|c|c|c|c|c|c|c|}
\hline \multicolumn{8}{|c|}{ 7a: Intra-Treatment Group Analyses } \\
\hline $\begin{array}{c}\text { Dexamethasone } \\
\text { addition }\end{array}$ & Event & Mean & Median & SD & $\begin{array}{c}\mathrm{P} \\
\text { value }\end{array}$ & Test & $\begin{array}{c}\text { Data Set } \\
\text { Characteristics }\end{array}$ \\
\hline \multicolumn{8}{|c|}{ Serum Aspartate Aminotransferase Levels (AST) (units/L) } \\
\hline$(-)$ & Day 0 & 52.6 & 47 & 24.7 & \multirow[t]{2}{*}{0.0024} & Wilcox & \multirow[t]{2}{*}{ Paired } \\
\hline$(-)$ & Discharge & 42.2 & 35 & 19.7 & & Rank & \\
\hline$(+)$ & Day 0 & 104.8 & 54.5 & 132.3 & \multirow[t]{2}{*}{0.355} & Wilcox & \multirow[t]{2}{*}{ Paired } \\
\hline$(+)$ & Discharge & 283.4 & 44 & 721.3 & & $\begin{array}{l}\text { Slgned } \\
\text { Rank }\end{array}$ & \\
\hline \multicolumn{8}{|c|}{ Serum Total Bilirubin Levels (mg/dL) } \\
\hline$(-)$ & Day 0 & 1.2 & 0.8 & 1.7 & \multirow[t]{2}{*}{0.0080} & Wilcox & \multirow[t]{2}{*}{ Paired } \\
\hline$(-)$ & Discharge & 0.69 & 0.6 & 0.45 & & Signed & \\
\hline$(+)$ & Day 0 & 0.95 & 0.9 & 0.46 & \multirow[t]{2}{*}{0.984} & Wilcox & \multirow[t]{2}{*}{ Paired } \\
\hline$(+)$ & Discharge & 1.21 & 0.8 & 0.96 & & $\begin{array}{l}\text { Slgned } \\
\text { Rank }\end{array}$ & \\
\hline
\end{tabular}

\begin{tabular}{|c|c|c|c|c|}
\hline \multicolumn{5}{|c|}{ 7b: Inter-Treatment Group Analyses } \\
\hline $\begin{array}{c}\text { Dexamethasone } \\
\text { addition }\end{array}$ & Event & P value & Test & Data Set Characteristics \\
\hline \multicolumn{5}{|c|}{ Serum Aspartate Aminotransferase Levels } \\
\hline$(-)$ & Day 0 & \multirow[t]{2}{*}{0.30} & \multirow[t]{2}{*}{ Mann-Whitney } & \multirow[t]{2}{*}{ Grouped } \\
\hline$(-)$ & Day 0 & & & \\
\hline$(+)$ & Discharge & \multirow[t]{2}{*}{0.57} & \multirow[t]{2}{*}{ Mann-Whitney } & \multirow{2}{*}{ Grouped } \\
\hline$(+)$ & Discharge & & & \\
\hline \multicolumn{5}{|c|}{ Serum Total Bilirubin Levels (mg/dL) } \\
\hline$(-)$ & Day 0 & \multirow[t]{2}{*}{0.57} & \multirow[t]{2}{*}{ Mann-Whitney } & \multirow[t]{2}{*}{ Grouped } \\
\hline$(+)$ & Day 0 & & & \\
\hline$(-)$ & Discharge & \multirow[t]{2}{*}{0.0012} & \multirow{2}{*}{ Mann-Whitney } & \multirow[t]{2}{*}{ Grouped } \\
\hline$(+)$ & Discharge & & & \\
\hline
\end{tabular}

\section{Biomarker summaries categorized by WHO category at enrollment}

To enable rapid review and comparative analysis of trends in biomarker responses between the two treatment groups as a function of disease severity at the time of enrollment, heatmap plots were developed for all patients in the famcox (-) dexamethasone (Fig. 9a) and famcox (+) dexamethasone 
(Fig. 9b) groups. To facilitate heatmap analysis, the pre- and post-treatment laboratory biomarker data were normalized to percent change from baseline expressed as the $\log _{10}$ transformed ratio of pretreatment value divided by post-treatment value. $\log _{10}$ transformation was used to compress value range to support heat map analysis due to skewing by occasional outlier values. After logarithmic transformation, the sign of the change (positive if improved, negative if deteriorated) was added prior to plotting. The data were then sorted by WHO score at time of admission into the study. Heatmap plots were generated for the risk factors of age and body mass index (BMI) as well as individual biomarker results for each patient. Laboratory biomarkers were clustered consistent with those used above. The plots suggest a clear trend towards deterioration of biomarker results during the treatment course in the famcox (+) dexamethasone group relative to the famcox (-) dexamethasone group, but do not show a marked intragroup difference between those enrolled at a WHO score of 4 or 5 .

\section{Discussion}

Our objective is to identify, test and clinically develop combinations of currently licensed pharmaceutical agents that show promise for reducing morbidity and mortality of acute and long term (chronic) COVID19. Ideally, these drug combinations would employ inexpensive, generic, off-patent oral pharmaceuticals that are readily manufactured, globally available, and thermostable. We have intentionally chosen to not file intellectual property claims on the combinations being tested in the interest of enabling global access to these combinations of repurposed drugs. By analogy to the successful development of pharmaceutical agent combinations for treatment of AIDS, ideal combinations would incorporate drugs with complementary mechanisms of action in the hope that this will reduce evolutionary escape opportunities for the diverse SARS-CoV-2 viral swarms generated during infection and replication in patients and populations. COVID-19 is a complicated multi-organ system disease which impacts on a wide range of fundamental physiology and regulatory pathways (Curran et al., 2020; Gupta et al., 2020; Koralnik and Tyler, 2020). Our focus has been on mitigating the hyperinflammatory cascade symptoms of both acute and chronic COVID-19 (Gustine and Jones, 2021; Nalbandian et al., 2021).

Building on our initial discovery of the activity and mechanism of action of the histamine $\mathrm{H} 2$ receptor inverse agonist famotidine for reducing COVID-19 symptoms (Malone, 2021; Malone et al., 2021), we have combined this agent with the COX-2 inhibitor celecoxib (Baghaki et al., 2020; Hong et al., 2020) to produce a binary treatment protocol (Tomera et al., 2021). This yielded an adjuvant anti-inflammatory combination with specific and well-characterized MOA which appears to provide potent clinical responses in hospitalized COVID-19 patients (Tomera et al., 2021). Both of these agents are off-patent, generic, inexpensive, widely available, have been administered for many years to many patients, and have extensive safety and drug-interaction databases. MOA, dosing and safety considerations for these agents when used to treat COVID-19 have been investigated and discussed in preceding publications (Hong et al., 2020; KM Tomera, 2020; Tomera and Kittah, 2020; Malone et al., 2021; Tomera et al., 2021). In brief, one working hypothesis is that viral activation of COX-2 expression in infected cells (Chen et al., 2021) (mediated by SARS-CoV-2 spike and nucleocapsid proteins (Yan et al., 2006; Liu et al., 2007)) drives production of elevated Prostaglandin E2 (PGE2) and related signaling molecules, mast cell/basophil 
recruitment and degranulation, and a self-reinforcing positive feedback loop with some features of mast cell activation syndrome. B cell activation is also associated with increased COX-2 expression and elevated levels of PGE2. Therefore, activated B cells could also be major or predominant drivers of elevated PGE2 levels (Kim et al., 2018) (Ryan et al., 2005) (Bryn et al., 2008). Elevated PGE2 is also associated with induction of FOXP3 + T cells (Treg). As COVID-19 disease progresses, FOXP3 + Treg cells become a major fraction of the overall CD $4+T$ cell population (Kaneko et al., 2020), correlating with and supporting the hypothesized role of COX-2/PGE2 in COVID-19 pathogenesis. Treg-mediated immunosuppression is a common characteristic of patients with prolonged COVID-19 disease course (Tang et al., 2020b). Depleted germinal centers are found in lymphoid tissues from COVID-19 patients examined at autopsy, and an early specific block in Bcl-6 + TFH cell differentiation combined with increased T-bet ${ }^{+}$TH1 cells and aberrant extra-follicular TNF-a accumulation may account for the dysregulated humoral immune response observed early in COVID-19 disease (Kaneko et al., 2020).

PGE2 elevations in COVID-19 disease may also be a consequence of renal impacts of SARS-CoV-2 on the RAAS pathway (Curran et al., 2020), which is involved in homeostatic control of extracellular volume, arterial pressure, tissue perfusion, electrolyte balance, and wound healing (Atlas, 2007; Ingraham et al., 2020). Sensors located within macula densa cells (which reside within the juxtaglomerular apparatus) control glomerular perfusion (and thereby glomerular filtration rate) via production of adenosine and ATP (Kriz, 2004; Peti-Peterdi and Harris, 2010). These cells also produce COX-2, which in turn produces PGE2 and other prostaglandins. Juxtaglomerular cells in the afferent glomerular arteriole then release pro-renin in response to stimulation by prostaglandins. Pro-renin is then proteolytically converted to active renin, which then cleaves angiotensin setting the ACE/Ang II/AT ${ }_{1} R$ cascade in motion. The SARS-CoV-2 receptor ACE2 functions as an endogenous inhibitor of the ACE/Ang II/AT1R pathway and opposes the vasoconstrictive, inflammatory, prothrombotic, and fibrotic effects associated with ACE/Ang II/AT ${ }_{1} R$ activity, but ACE2 is downregulated upon binding and uptake during SARS-CoV-2 infection. Prolonged dysregulation in the RAAS system promotes renal and cardiovascular diseases (Munoz and Covenas, 2014). In acute pulmonary infections, the RAAS pathway contributes to the development of acute respiratory distress syndrome (ARDS) and subsequent pulmonary fibrosis (Kuba et al., 2006), which is often associated with COVID-19 (Zhu et al., 2020).

Whatever the principal drivers of COX-2 expression in COVID-19 and associated elevated PGE2 levels, celecoxib is the only specific COX-2 inhibitor currently authorized for marketing by the US FDA. This combination of repurposed drugs is based on the labeled MOA of famotidine and celecoxib as antiinflammatory agents. To distinguish from suboptimal treatment protocols which typically employ inadequate doses of famotidine (Malone, 2021; Shoaibi et al., 2021; Sun et al., 2021), this binary drug combination is referred to as High Dose (HD) famotidine + celecoxib or famcox.

Dexamethasone, a glucocorticoid receptor agonist, is an anti-inflammatory corticosteroid with relatively high affinity for the alpha subunit of the glucocorticoid receptor (GRa). The potency of GRa agonists are typically measured based on suppression of lymphocyte proliferation, and the wide range of mechanisms of action may be grouped as genomic, non-genomic, and mitochondrial signaling pathway responses 
(Meduri et al., 2020). GRa plays a central role in all phases of development and resolution of host inflammatory responses, including activation and re-enforcement of innate immunity, downregulation of pro-inflammatory transcription factors, and restoration of anatomy and function (Meduri and Chrousos, 2020). The three general pathway categories (genomic, non-genomic, mitochondrial) differ in sensitivity ( $E C_{50}$ or $\mathrm{IC}_{50}$ ) to agonist binding; glucocorticoids generally have higher potency for genomic (ergo transcriptional regulation) than non-genomic effects. Genomic effects include regulation of a wide variety of genes including those involved in histamine metabolism (Juszczak and Stankiewicz, 2018). Nongenomic effects include inhibition of prostaglandin E2 (PGE2) and arachidonic acid release through suppression of phospholipase A2 synthesis. Therefore, the broad-spectrum, dose-dependent, relatively non-specific clinical activity of dexamethasone overlaps with the specific activities of famotidine and celecoxib.

Corticosteroids have a profound effect on the concentration of peripheral blood leukocytes. Lymphocyte, monocyte, and basophil counts decrease in response to corticosteroid administration, while neutrophil counts increase. The peak effects are seen within 4 to 6 hours after a dose of corticosteroid.

Glucocorticoids including dexamethasone also have profound effects on cellular functions of leukocytes and endothelial cells, which in aggregate reduce the ability of leukocytes to adhere to vascular endothelium and exit from the circulation, leading to a neutrophilia. Entry to sites of infection and tissue injury is impaired, resulting in suppression of the inflammatory response (Fauci et al., 1976; Fauci et al., 1980; Boumpas et al., 1993). Functional properties of monocytes including phagocytosis and microbial killing are particularly susceptible to glucocorticoid suppression at clinically relevant doses. The observed reduction in endothelial adhesion may be due to direct effects of glucocorticoids on expression of adhesion molecules on both leukocytes and endothelial cells, as well as indirect effects due to the inhibitory effects of glucocorticoids on transcription of cytokines, such as IL-1 or tumor necrosis factor (TNF), which upregulate endothelial adhesion molecule expression.

The prospective randomized RECOVERY platform clinical trial has previously examined the use of dexamethasone in hospitalized COVID-19 patients (Recovery_Collaborative_Group et al., 2020; 2021), and the two interim reports of study outcomes have triggered widespread use of dexamethasone for treatment of COVID-19 throughout much of the world including the United States. The initial interim result publication was criticized for "limitations and cause for caution" (Mahase, 2020), specifically "The authors have used relative reductions and chosen the subgroup with the biggest benefit to generate a headline of a one third reduction in deaths. The subgroup analysis was not specified in the trial registry and may be misleading.". After age adjustment, the preliminary second interim analysis of the RECOVERY dexamethasone data indicated a beneficial effect on 28-day mortality of patients receiving invasive mechanical ventilation ( $29.3 \%$ vs. $41.4 \% ; 12.1 \%$ ), a modest impact on 28 -day mortality for those receiving oxygen without invasive mechanical ventilation ( $23.3 \%$ vs. $26.2 \% ; 2.9 \%)$, and no statistically significant effect on those who were receiving no respiratory support at randomization (17.8\% vs. $14.0 \% ;-3.8 \%)$. These apparent benefits were restricted to those less than 70 years old; for patients aged greater than 70 years, no statistically significant benefit was observed on 28-day mortality associated with 
dexamethasone adjuvant treatment. No statistically significant 28-day mortality benefits were observed for enrolled patients identified as "white" race; only among patients identified as "Black, Asian, of minority ethnic group" or of unknown race. Similarly, subgroup analysis by gender supported statistically significant benefit for males only. Adjuvant treatment with dexamethasone was not associated with reduced 28-day mortality among those reporting less than 8 days of COVID symptoms; reduction in 28day mortality was restricted to only those with a longer period since symptom onset. Secondary outcome findings from this second interim analysis included a one-day shorter duration of hospitalization (median, 12 days vs. 13 days), and greater probability of discharge alive within 28 days $(67.2 \%$ vs. $63.5 \% ; 3.7 \%)$ with the largest effect observed in patients receiving invasive mechanical ventilation at randomization. Demonstration of these statistically significant findings required a large patient population $-2,104$ patients were enrolled in the dexamethasone + usual care arm, and 4,321 in the usual care arm. Despite the large study population, demonstration of statistical significance required age adjustment, and without age adjustment statistical significance was not reached. Risk of progression to invasive mechanical ventilation was also lower in the dexamethasone group relative to standard of care. Not yet reported for this trial are the effects of dexamethasone on cause-specific mortality, the need for renal dialysis or hemofiltration, and the duration of ventilation. Unknown at this time are the long-term effects of dexamethasone treatment of COVID-19 patients, including the risk for development of the post-acute COVID syndrome (long COVID or post-Acute Sequelae of SARS-CoV-2 infection; e.g PASC) after broadspectrum immunosuppression during the acute phase of disease.

In many US hospital settings, subsequent to publication of the RECOVERY trial data, dexamethasone has become standard of care at all stages of hospitalized COVID-19 disease, and this broad-spectrum immunosuppressive agent is often administered to non-hospitalized patients who are not receiving supplemental oxygen. This over-use and broadening of indications beyond those supported by current clinical data is reminiscent of the prior widespread global consensus concerning use of hydroxychloroquine for treating both outpatient and inpatient COVID. A comprehensive meta-analysis of randomized clinical trial data involving use of corticosteroids for COVID-19 patients being treated in intensive care units (including data from the RECOVERY trial) demonstrated that "patients with COVID-19 who might benefit from corticosteroids therapy are a small minority". This meta-analysis report concludes that "use of corticosteroids may be considered in severe critically ill patients with COVID-19 but must be discouraged in all patients who do not require oxygen support. Given the small effect on survival of critically ill patients, they must be compared with other anti-inflammatory drugs" (Pasin et al., 2021). Broad spectrum, non-specific immunosuppression for treating COVID-19 hyperinflammation may dampen the effects of cytokine storm but does so at the expense of anti-viral Type 1 interferon responses and adaptive cellular and humoral immunity (Thomas et al., 2014; Singanayagam et al., 2018; Ritchie and Singanayagam, 2020).

The abrupt introduction of dexamethasone into the usual management of hospitalized COVID-19 at Beloit Memorial hospital (which included adjuvant famcox in most cases) created a unique opportunity to perform a natural experiment; a retrospective comparison study of sequential continuous hospitalized COVID-19 cohorts treated without or with added dexamethasone. In the hierarchy of clinical evidence 
upon which clinical management decisions should be based, randomized controlled trials (Level I) are followed by cohort studies (Level II), case-control studies (Level III), case series (Level IV), and expert opinion (Level V) (Brighton et al., 2003). Herein, we report a retrospective observational comparative cohort study, which is one form of a case-control study (Level III). The clinical data reported herein provides an initial analysis of the effects of dexamethasone treatment in addition to the antiinflammatory adjuvant combination of HD famotidine + celecoxib. Given the modest number of patients enrolled in this comparative retrospective study, it is remarkable that the addition of dexamethasone to famcox and usual care yields such striking, statistically significant differences in the time required to reach improvement in clinical status to WHO $<4$ ( 3.5 days vs. 10 days), overall mortality ( $0 \%$ vs.29\%), and a wide range of laboratory biomarker analysis results. Particularly notable is that the clear and consistent positive trends in biomarkers relevant to COVID-19 prognosis observed with famcox adjuvant treatment are no longer present when dexamethasone is added to the treatment regime (Figs. 3 through 8 and Tables 3 through 7).

Dexamethasone, like other glucocorticoids, causes leukocytosis. This clinical response is dominated by increased numbers of circulating neutrophils; in clinical practice glucocorticoids inhibit lymphocyte proliferation and function. This side effect of dexamethasone is more than theoretical. COVID-19 related neutrophilia and lymphophenia, typically measured by the neutrophil lymphocyte ratio (NLR), is associated with morbidity and mortality (Gottlieb et al., 2020; Qin et al., 2020). Even with these small cohorts, comparative laboratory biomarker analysis of lymphocyte fraction $(P=0.0005)$, absolute neutrophil count comparison $(P=0.0001)$, and the neutrophil and lymphocyte ratio $(P=0.0019)$ all met criteria for statistically significant improvement at study exit in the famcox (-) dexamethasone group compared to the $(+)$ dexamethasone cohort. These data suggest that addition of broad spectrum pharmaceutical immunosuppression using corticosteroids must indeed be "compared with other antiinflammatory drugs", and that the targeted famcox antihistamine/COX-2 anti-inflammatory strategy should not be combined with potent broad spectrum, non-specific immunosuppression when treating COVID-19. However, conclusive analysis of this preliminary observation will require larger prospective randomized clinical trials. A Phase 2 open label randomized clinical trial of HD famotidine, celecoxib, dexamethasone and remdesivir in severe hospitalized COVID-19 is currently enrolling (I-Spy COVID-19 trial NCT04488081). In this trial, the sponsor (Quantum Leap Healthcare Collaborative) determined that the data summarized above were insufficient to justify withholding dexamethasone in the selected patient population based on the RECOVERY trial findings and has proceed with assessing the treatment protocol together with dexamethasone. Results of this clinical trial are pending, and may confirm the effects of adding dexamethasone to HD famotidine + celecoxib when treating hospitalized COVID-19 patients reported herein.

This study builds upon previously published original research, a case report, and a case series report concerning use of High Dose famotidine for COVID-19 treatment (Janowitz et al., 2020; Malone et al., 2021), a prospective randomized controlled trial of celecoxib for COVID-19 treatment (Hong et al., 2020), and a detailed case series and reports involving COVID-19 treatment with the combination of High Dose famotidine + celecoxib (Tomera and Kittah, 2020; Tomera et al., 2020; 2021). A key weakness in this 
comparative consecutive cohort analysis is that this study design is not able to control for all factors (known, unknown and unknowable) that differ between the two cohorts at the point of enrollment into the study, and so is subject to uncontrolled confounding during group selection. Another weakness is the absence of data from this site involving standard of care with added dexamethasone without famotidine and celecoxib treatment, as well as an absence of data involving standard of care alone (during this timeframe) without these adjuvant treatments. Because this is a retrospective comparison of findings from a natural experiment which occurred due to the ongoing rapid evolution of COVID-19 treatment protocols during the current crisis, historic data involving outcomes from standard of care prior to initial introduction of famotidine and celecoxib into this community hospital setting do not represent current best management practices in this setting and timeframe. As a consequence, analyses regarding the full effects of dexamethasone in addition to standard of care in this hospital setting and with this population cannot be performed. Reliance on a single hospital site and continuous accrual into each cohort based on date of admission may partially mitigate confounding due to selection bias. A rigorous assessment of the relative effects of HD famotidine + celecoxib (famcox) versus standard of care (with or without dexamethasone) will require a prospective, placebo controlled, blinded and randomized trial. Based on these accumulated findings, one Phase 2 open label randomized controlled trial has begun enrollment (NCT04488081), and two additional well powered prospective, blinded, randomized controlled trials are in late-stage planning (one in an outpatient population, one in newly admitted inpatients).

\section{Conclusion}

The overall objective of this retrospective observational comparative cohort study was to provide an initial estimate of the potential benefits, risks, prognosis and diagnostic laboratory findings associated with administration of dexamethasone in addition to High Dose (HD) famotidine and celecoxib (famcox) for treatment of newly hospitalized COVID-19 disease in a community hospital setting. In this study, the $\mathrm{HD}$ famotidine + celecoxib group serves as the active control for the HD famotidine + celecoxib + dexamethasone group. Addition of dexamethasone is the experimental variable. Study strengths include a) comparison of two continuous cohorts drawn sequentially from a single community hospital, b) the reported outcomes rely on objective rather than subjective measures, and c) multiple clinically significant objective outcome variables are analyzed and reported. A key weakness is that this study design is not able to control for all factors (known, unknown and unknowable) that differ between the two cohorts at the point of enrollment into the study, and so is subject to uncontrolled confounding during group selection. Reliance on a single hospital site and continuous accrual into each cohort based on date of admission may reduce this source of selection bias. A second key weakness is absence of cohorts treated with standard of care with or without dexamethasone. Lack of these controls precludes comparison to mortality and time to event outcomes under these conditions.

We report characteristics, analysis and outcomes of this natural clinical experiment comparing the effects of HD famotidine + celecoxib in addition to usual care to effects of HD famotidine + celecoxib + dexamethasone in addition to usual care. Patient inclusion criteria and primary outcome analyses were pre-defined. Primary analysis findings included statistically significant differences in the time to event for 
progression to WHO category 3 or less $(\mathrm{WHO}<4)$ comparison of control (famcox $(-)$ dex) and treatment (famcox (+) dex) groups [Log-rank (Mantel-Cox) test chi squared value of 20.19, P value of $<0.0001$ ], and curve comparison using the Gehan-Breslow-Wilcoxon (chi squared value of 21.46, P value of $<0.0001$ ). Median time to event for reaching WHO score of $<4$ was 3.5 days in the control group (famcox $(-)$ dex) versus 10 days for the experimental group (famcox (+) dex). Hazard Ratio (Mantel-Haenszel) for the treatment group ((+) dex) relative to control group ((-) dex) was 7.23 (95\% confidence interval of 3.05 to 17.14). Hazard Ratio (log rank) for the treatment group relative to the control group was 3.43 (95\% confidence interval of 1.64 to 7.17). Differences in cumulative mortality during hospitalization in the two treatment groups were also significantly different. In the group receiving adjuvant treatment with HD famotidine + celecoxib (without added dexamethasone), all enrolled patients were successfully discharged; there were no deaths during hospitalization $(0 / 18=0 \%$ mortality). A total of six deaths were recorded during hospitalization in the group receiving $\mathrm{HD}$ famotidine + celecoxib + dexamethasone $(6 / 21$ $=29 \%$ mortality). Of these deaths, four had been admitted and enrolled at WHO grade 5 , and two admitted and enrolled at WHO grade 4. Of those enrolled at WHO grade 4, death occurred at days 18 and 20 post enrollment. For those enrolled at WHO grade 5 , death occurred at days $9,11,12$, and 17 . Chi squared comparison of these outcomes was performed, with $2 \times 2$ table comparison of outcome (discharged or deceased) and treatment group ((-) or (+) dexamethasone (Stata v14.2). Results demonstrate that there was a significant difference in mortality between the two groups, $X^{2}(1, N=43)=$ $7.305, p<0.007$. We conclude from both this study and the RELIANCE study data that use of the potent non-specific anti-inflammatory corticosteroid dexamethasone in addition to the specific antiinflammatory HD famotidine and celecoxib protocol should only be considered in late stage COVID-19 disease in patients less than 70 years of age. Furthermore, the effects of added dexamethasone on laboratory biomarkers, and particularly on neutrophil count, lymphocyte count, and neutrophil to lymphocyte ratio raise concerns about the long term effects of dexamethasone treatment with or without famcox during acute COVID-19 on the incidence and severity of chronic COVID ("Iong COVID" or PASC) which may at least partially be attributable to dysregulation of myeloid and lymphoid compartments during acute COVID-19 (De Biasi et al., 2020; Duan et al., 2020; Kaneko et al., 2020; Schulte-Schrepping et al., 2020; Vabret et al., 2020; Perez-Gomez et al., 2021; Su et al., 2021). If dexamethasone is to be considered for use together with famcox in the narrowly defined cohort of severe hospitalized COVID-19 patients aged less than 70 years as supported by the RECOVERY trial data, then laboratory biomarker findings (in particular the neutrophil to lymphocyte ratio) should be carefully monitored.

\section{Declarations}

\section{ACKNOWLEDGMENTS}

The authors thank Dr. Revell Phillips for supportive advice and comments during the design phase of this study, and for review and editing recommendations to this manuscript. The authors acknowledge support provided for this assistance by the Department of Defense (DoD), Defense Threat Reduction Agency (DTRA), and the Joint Science and Technology Office (JSTO) of the Chemical and Biological Defense 
Program (CBDP) under the Discovery of Medical countermeasures Against Novel Entities (DOMANE) initiative. This support has been provided under Air Force Contract No. FA8702-15-D-0001. Any opinions, findings, conclusions, or recommendations expressed in this material are those of the author(s) and do not necessarily reflect the views of the U.S. Air Force.

This study has been conducted under approval of the Beloit Memorial Health System Institutional Review Board (IORG001171, file 20-05-1).

\section{AUTHOR CONTRIBUTIONS}

Conceptualization, RWM, KMT, and JKK; methodology, RWM, KMT and JKK.; software, RWM.; validation, RWM, KMT, JKK.; formal analysis, RWM, KMT.; investigation, KMT, LE, JKK.; resources, KMT.; data curation, KMT.; writing-original draft preparation RWM.; writing-review and editing, RWM, KMT, LE, JKK; supervision, JJK.; project administration, RWM, KMT.; funding acquisition, RWM. All authors have read and agreed to the published version of the manuscript.

\section{CONFLICT OF INTEREST STATEMENT}

Author Robert Malone was employed by RW Malone MD LLC, performing as a consultant to MIT Lincoln Laboratories, and subcontractor to Leidos, and Quantum Leap Healthcare Collaborative (QLHC) under contracts or MCDC consortium agreements issued by the US Department of Defense (DoD), Defense Threat Reduction Agency (DTRA), and the Joint Science and Technology Office (JSTO) of the Chemical and Biological Defense Program (CBDP) under the Discovery of Medical countermeasures Against Novel Entities (DOMANE) initiative. The consultant work support for this manuscript has been provided under Air Force Contract No. FA8702-15-D-0001, and for Leidos and QLHC under MCDC-2015-003 and MCDC2013-001. Dr. Malone reports personal fees and other from MIT Lincoln Laboratories/RW Malone MD LLC during the conduct of the study; COVID-related compensation outside the submitted work includes personal fees and other from Leidos/RW Malone MD LLC, personal fees and other from Quantum Leap Healthcare Collaborative/RW Malone MD LLC, personal fees from Alchem corporation, personal fees from Evergreen Therapeutics/RW Malone MD LLC, personal fees from Chrysalis Biotherapeutics/RW Malone MD LLC, personal fees from Reliance Vaccines/RW Malone MD LLC, personal fees from Puma Biotechnology/RW Malone MD LLC, personal fees from Nanobiosym/RW Malone MD LLC, personal fees from ID-Tech Molecular Laboratories/RW Malone MD LLC. Dr. Malone received royalty payments for the book "Novel Coronavirus: A guide for preparation and protection" published 11 Feb 2020. Author Kevin Tomera was employed by the Beloit Memorial Hospital Department of Urology and declares that the research was conducted in the absence of any commercial or financial relationships that could be construed as a potential conflict of interest. Author Leo Egbujiobi was employed by the Beloit Memorial Hospital Cardiology Department and declares that the research was conducted in the absence of any commercial or financial relationships that could be construed as a potential conflict of interest. Author Joseph Kittah was employed by the Beloit Memorial Hospital Pulmonary Department and declares that the research was conducted in the absence of any commercial or financial relationships that could be construed as a potential conflict of interest. No intellectual property, patent rights or commercialization 
rights have been filed or are being pursued by the authors or their affiliated employers or contractors for the pharmaceutical agents or combinations which are the subject of this manuscript.

\section{References}

Atlas, S.A. (2007). The renin-angiotensin aldosterone system: pathophysiological role and pharmacologic inhibition. J Manag Care Pharm 13(8 Suppl B), 9-20. doi: 10.18553/jmcp.2007.13.s8-b.9.

Baghaki, S., Yalcin, C.E., Baghaki, H.S., Aydin, S.Y., Daghan, B., and Yavuz, E. (2020). COX2 inhibition in the treatment of COVID-19: Review of literature to propose repositioning of celecoxib for randomized controlled studies. Int J Infect Dis 101, 29-32. doi: 10.1016/j.ijid.2020.09.1466.

Bajwa, E.K., Khan, U.A., Januzzi, J.L., Gong, M.N., Thompson, B.T., and Christiani, D.C. (2009). Plasma Creactive protein levels are associated with improved outcome in ARDS. Chest 136(2), 471-480. doi: 10.1378/chest.08-2413.

Boumpas, D.T., Chrousos, G.P., Wilder, R.L., Cupps, T.R., and Balow, J.E. (1993). Glucocorticoid therapy for immune-mediated diseases: basic and clinical correlates. Ann Intern Med 119(12), 1198-1208. doi: 10.7326/0003-4819-119-12-199312150-00007.

Brighton, B., Bhandari, M., Tornetta, P., 3rd, and Felson, D.T. (2003). Hierarchy of evidence: from case reports to randomized controlled trials. Clin Orthop Relat Res (413), 19-24. doi:

10.1097/01.blo.0000079323.41006.12.

Bryn, T., Yaqub, S., Mahic, M., Henjum, K., Aandahl, E.M., and Tasken, K. (2008). LPS-activated monocytes suppress T-cell immune responses and induce FOXP3+ T cells through a COX-2-PGE2-dependent mechanism. Int Immunol 20(2), 235-245. doi: 10.1093/intimm/dxm134.

Chan, J.F., Yuan, S., Kok, K.H., To, K.K., Chu, H., Yang, J., et al. (2020). A familial cluster of pneumonia associated with the 2019 novel coronavirus indicating person-to-person transmission: a study of a family cluster. Lancet 395(10223), 514-523. doi: 10.1016/S0140-6736(20)30154-9.

Chen, J.S., Alfajaro, M.M., Chow, R.D., Wei, J., Filler, R.B., Eisenbarth, S.C., et al. (2021). Non-steroidal antiinflammatory drugs dampen the cytokine and antibody response to SARS-CoV-2 infection. J Virol. doi: 10.1128/JVI.00014-21.

Curran, C.S., Rivera, D.R., and Kopp, J.B. (2020). COVID-19 Usurps Host Regulatory Networks. Front Pharmacol 11, 1278. doi: 10.3389/fphar.2020.01278.

De Biasi, S., Lo Tartaro, D., Meschiari, M., Gibellini, L., Bellinazzi, C., Borella, R., et al. (2020). Expansion of plasmablasts and loss of memory B cells in peripheral blood from COVID-19 patients with pneumonia. Eur J Immunol 50(9), 1283-1294. doi: 10.1002/eji.202048838. 
Duan, Y.Q., Xia, M.H., Ren, L., Zhang, Y.F., Ao, Q.L., Xu, S.P., et al. (2020). Deficiency of Tfh Cells and Germinal Center in Deceased COVID-19 Patients. Curr Med Sci 40(4), 618-624. doi: 10.1007/s11596-0202225-x.

Elshazli, R.M., Toraih, E.A., Elgaml, A., El-Mowafy, M., El-Mesery, M., Amin, M.N., et al. (2020). Diagnostic and prognostic value of hematological and immunological markers in COVID-19 infection: A metaanalysis of 6320 patients. PLoS One 15(8), e0238160. doi: 10.1371/journal.pone.0238160.

Fauci, A.S., Dale, D.C., and Balow, J.E. (1976). Glucocorticosteroid therapy: mechanisms of action and clinical considerations. Ann Intern Med 84(3), 304-315. doi: 10.7326/0003-4819-84-3-304.

Fauci, A.S., Murakami, T., Brandon, D.D., Loriaux, D.L., and Lipsett, M.B. (1980). Mechanisms of corticosteroid action on lymphocyte subpopulations. VI. Lack of correlation between glucocorticosteroid receptors and the differential effects of glucocorticosteroids on T-cell subpopulations. Cell Immunol 49(1), 43-50. doi: 10.1016/0008-8749(80)90054-4.

Gottlieb, M., Sansom, S., Frankenberger, C., Ward, E., and Hota, B. (2020). Clinical Course and Factors Associated with Hospitalization and Critical IIIness Among COVID-19 Patients in Chicago, Illinois. Acad Emerg Med. doi: 10.1111/acem.14104.

Gupta, A., Madhavan, M.V., Sehgal, K., Nair, N., Mahajan, S., Sehrawat, T.S., et al. (2020). Extrapulmonary manifestations of COVID-19. Nat Med26(7), 1017-1032. doi: 10.1038/s41591-020-0968-3.

Gustine, J.N., and Jones, D. (2021). Immunopathology of Hyperinflammation in COVID-19. Am J Pathol 191(1), 4-17. doi: 10.1016/j.ajpath.2020.08.009.

He, G., Sun, W., Fang, P., Huang, J., Gamber, M., Cai, J., et al. (2020). The clinical feature of silent infections of novel coronavirus infection (COVID-19) in Wenzhou. J Med Virol. doi: 10.1002/jmv.25861.

Hong, W., Chen, Y., You, K., Tan, S., Wu, F., Tao, J., et al. (2020). Celebrex Adjuvant Therapy on Coronavirus Disease 2019: An Experimental Study. Frontiers in Pharmacology 11(1795). doi:

10.3389/fphar.2020.561674.

Hu, Z., Song, C., Xu, C., Jin, G., Chen, Y., Xu, X., et al. (2020). Clinical characteristics of 24 asymptomatic infections with COVID-19 screened among close contacts in Nanjing, China. Sci China Life Sci 63(5), 706711. doi: 10.1007/s11427-020-1661-4.

Huang, C., Wang, Y., Li, X., Ren, L., Zhao, J., Hu, Y., et al. (2020). Clinical features of patients infected with 2019 novel coronavirus in Wuhan, China. Lancet 395(10223), 497-506. doi: 10.1016/S01406736(20)30183-5.

Ing, A.J., Cocks, C., and Green, J.P. (2020). COVID-19: in the footsteps of Ernest Shackleton. Thorax. doi: 10.1136/thoraxjnl-2020-215091. 
Ingraham, N.E., Barakat, A.G., Reilkoff, R., Bezdicek, T., Schacker, T., Chipman, J.G., et al. (2020). Understanding the renin-angiotensin-aldosterone-SARS-CoV axis: a comprehensive review. Eur Respir J 56(1). doi: 10.1183/13993003.00912-2020.

Janowitz, T., Gablenz, E., Pattinson, D., Wang, T.C., Conigliaro, J., Tracey, K., et al. (2020). Famotidine use and quantitative symptom tracking for COVID-19 in non-hospitalised patients: a case series. Gut. doi: 10.1136/gutjnl-2020-321852.

Juszczak, G.R., and Stankiewicz, A.M. (2018). Glucocorticoids, genes and brain function. Prog Neuropsychopharmacol Biol Psychiatry 82, 136-168. doi: 10.1016/j.pnpbp.2017.11.020.

Kaneko, N., Kuo, H.H., Boucau, J., Farmer, J.R., Allard-Chamard, H., Mahajan, V.S., et al. (2020). Loss of Bcl-6-Expressing T Follicular Helper Cells and Germinal Centers in COVID-19. Cell 183(1), 143-157 e113. doi: 10.1016/j.cell.2020.08.025.

Kellum, J.A., Lameire, N., and Group, K.A.G.W. (2013). Diagnosis, evaluation, and management of acute kidney injury: a KDIGO summary (Part 1). Crit Care 17(1), 204. doi: 10.1186/cc11454.

Kim, J., Lee, S., Jeoung, D., Kim, Y.M., and Choe, J. (2018). Activated human B cells stimulate COX-2 expression in follicular dendritic cell-like cells via TNF-alpha. Mol Immunol 94, 1-6. doi: 10.1016/j.molimm.2017.12.004.

Kishaba, T., Tamaki, H., Shimaoka, Y., Fukuyama, H., and Yamashiro, S. (2014). Staging of acute exacerbation in patients with idiopathic pulmonary fibrosis. Lung 192(1), 141-149. doi: 10.1007/s00408013-9530-0.

KM Tomera, R.M., JK Kittah (2020). Brief Report: Rapid Clinical Recovery from Severe COVID-19 with High Dose Famotidine

and High Dose Celecoxib Adjuvant Therapy. Enliven: Pharmacovigilance and Drug Safety 6(3).

Koralnik, I.J., and Tyler, K.L. (2020). COVID-19: A Global Threat to the Nervous System. Ann Neuro/ 88(1), 1-11. doi: 10.1002/ana.25807.

Kriz, W. (2004). Adenosine and ATP: traffic regulators in the kidney. J Clin Invest 114(5), 611-613. doi: $10.1172 / \mathrm{JCl} 22669$.

Kronbichler, A., Kresse, D., Yoon, S., Lee, K.H., Effenberger, M., and Shin, J.I. (2020). Asymptomatic patients as a source of COVID-19 infections: A systematic review and meta-analysis. Int J Infect Dis 98, 180-186. doi: 10.1016/j.ijid.2020.06.052.

Kuba, K., Imai, Y., and Penninger, J.M. (2006). Angiotensin-converting enzyme 2 in lung diseases. Curr Opin Pharmacol 6(3), 271-276. doi: 10.1016/j.coph.2006.03.001. 
Lei, F., Liu, Y.M., Zhou, F., Qin, J.J., Zhang, P., Zhu, L., et al. (2020). Longitudinal Association Between Markers of Liver Injury and Mortality in COVID-19 in China. Hepatology 72(2), 389-398. doi:

10.1002/hep.31301.

Lin, Z., Long, F., Yang, Y., Chen, X., Xu, L., and Yang, M. (2020). Serum ferritin as an independent risk factor for severity in COVID-19 patients. J Infect. doi: 10.1016/j.jinf.2020.06.053.

Liu, M., Yang, Y., Gu, C., Yue, Y., Wu, K.K., Wu, J., et al. (2007). Spike protein of SARS-CoV stimulates cyclooxygenase-2 expression via both calcium-dependent and calcium-independent protein kinase $\mathrm{C}$ pathways. FASEB J 21(7), 1586-1596. doi: 10.1096/fj.06-6589com.

Long, Q.X., Tang, X.J., Shi, Q.L., Li, Q., Deng, H.J., Yuan, J., et al. (2020). Clinical and immunological assessment of asymptomatic SARS-CoV-2 infections. Nat Med. doi: 10.1038/s41591-020-0965-6.

Mahase, E. (2020). Covid-19: Demand for dexamethasone surges as RECOVERY trial publishes preprint. BMJ 369, m2512. doi: 10.1136/bmj.m2512.

Malone, R. (2021). More Than Just Heartburn: Does Famotidine Effectively Treat Patients with COVID-19? (Epub ahead of print) Digestive Diseases and Sciences. doi: 10.1007/s10620-021-06875-w.

Malone, R., Tisdall, P., Fremont-Smith, P., Liu, Y., Huang, X.-P., White, K., et al. (2021). COVID-19: Famotidine, Histamine, Mast Cells, and Mechanisms. (In Press) Frontiers in Pharmacology. doi: 10.21203/rs.3.rs30934/v1.

Meduri, G.U., Annane, D., Confalonieri, M., Chrousos, G.P., Rochwerg, B., Busby, A., et al. (2020). Pharmacological principles guiding prolonged glucocorticoid treatment in ARDS. Intensive Care Med 46(12), 2284-2296. doi: 10.1007/s00134-020-06289-8.

Meduri, G.U., and Chrousos, G.P. (2020). General Adaptation in Critical Illness: Glucocorticoid Receptoralpha Master Regulator of Homeostatic Corrections. Front Endocrinol (Lausanne) 11, 161. doi: 10.3389/fendo.2020.00161.

Mizumoto, K., Kagaya, K., Zarebski, A., and Chowell, G. (2020). Estimating the asymptomatic proportion of coronavirus disease 2019 (COVID-19) cases on board the Diamond Princess cruise ship, Yokohama, Japan, 2020. Euro Surveill 25(10). doi: 10.2807/1560-7917.ES.2020.25.10.2000180.

Munoz, M., and Covenas, R. (2014). Involvement of substance P and the NK-1 receptor in human pathology. Amino Acids 46(7), 1727-1750. doi: 10.1007/s00726-014-1736-9.

Nalbandian, A., Sehgal, K., Gupta, A., Madhavan, M.V., McGroder, C., Stevens, J.S., et al. (2021). Post-acute COVID-19 syndrome. Nat Med. doi: 10.1038/s41591-021-01283-z.

Pasin, L., Navalesi, P., Zangrillo, A., Kuzovlev, A., Likhvantsev, V., Hajjar, L.A., et al. (2021). Corticosteroids for Patients With Coronavirus Disease 2019 (COVID-19) With Different Disease Severity: A Meta-Analysis 
of Randomized Clinical Trials. J Cardiothorac Vasc Anesth 35(2), 578-584. doi: 10.1053/j.jvca.2020.11.057.

Perez-Gomez, A., Vitalle, J., Gasca-Capote, M.C., Gutierrez-Valencia, A., Trujillo-Rodriguez, M., SernaGallego, A., et al. (2021). Dendritic cell deficiencies persist seven months after SARS-CoV-2 infection. bioRxiv, 2021.2003.2018.436001. doi: 10.1101/2021.03.18.436001.

Peti-Peterdi, J., and Harris, R.C. (2010). Macula densa sensing and signaling mechanisms of renin release. J Am Soc Nephro/ 21(7), 1093-1096. doi: 10.1681/ASN.2009070759.

Potempa, L.A., Rajab, I.M., Hart, P.C., Bordon, J., and Fernandez-Botran, R. (2020). Insights into the Use of C-Reactive Protein as a Diagnostic Index of Disease Severity in COVID-19 Infections. Am J Trop Med Hyg. doi: 10.4269/ajtmh.20-0473.

Qin, C., Zhou, L., Hu, Z., Zhang, S., Yang, S., Tao, Y., et al. (2020). Dysregulation of Immune Response in Patients With Coronavirus 2019 (COVID-19) in Wuhan, China. Clin Infect Dis 71(15), 762-768. doi: $10.1093 /$ cid/ciaa248.

Recovery_Collaborative_Group, Horby, P., Lim, W.S., Emberson, J.R., Mafham, M., Bell, J.L., et al. (2020). Dexamethasone in Hospitalized Patients with Covid-19 - Preliminary Report. N Engl J Med. doi: 10.1056/NEJMoa2021436.

Recovery_Collaborative_Group, Horby, P., Lim, W.S., Emberson, J.R., Mafham, M., Bell, J.L., et al. (2021). Dexamethasone in Hospitalized Patients with Covid-19. N Engl J Med 384(8), 693-704. doi:

10.1056/NEJMoa2021436.

Ridker, P.M., Danielson, E., Fonseca, F.A., Genest, J., Gotto, A.M., Jr., Kastelein, J.J., et al. (2008). Rosuvastatin to prevent vascular events in men and women with elevated C-reactive protein. N Engl J Med 359(21), 2195-2207. doi: 10.1056/NEJMoa0807646.

Ritchie, A.I., and Singanayagam, A. (2020). Immunosuppression for hyperinflammation in COVID-19: a double-edged sword? Lancet 395(10230), 1111. doi: 10.1016/S0140-6736(20)30691-7.

Ruuskanen, O., Lahti, E., Jennings, L.C., and Murdoch, D.R. (2011). Viral pneumonia. Lancet 377(9773), 1264-1275. doi: 10.1016/S0140-6736(10)61459-6.

Ryan, E.P., Pollock, S.J., Murant, T.I., Bernstein, S.H., Felgar, R.E., and Phipps, R.P. (2005). Activated human B lymphocytes express cyclooxygenase-2 and cyclooxygenase inhibitors attenuate antibody production. J Immunol 174(5), 2619-2626. doi: 10.4049/jimmunol.174.5.2619.

Schulte-Schrepping, J., Reusch, N., Paclik, D., Bassler, K., Schlickeiser, S., Zhang, B., et al. (2020). Severe COVID-19 Is Marked by a Dysregulated Myeloid Cell Compartment. Cell 182(6), 1419-1440 e1423. doi: 10.1016/j.cell.2020.08.001. 
Sharma, S.K., Gupta, A., Biswas, A., Sharma, A., Malhotra, A., Prasad, K.T., et al. (2016). Aetiology, outcomes \& predictors of mortality in acute respiratory distress syndrome from a tertiary care centre in north India. Indian J Med Res 143(6), 782-792. doi: 10.4103/0971-5916.192063.

Shoaibi, A., Fortin, S., Weinstein, R., Berlin, J., and Ryan, P. (2021). Comparative Effectiveness of Famotidine in Hospitalized COVID-19 Patients short title: Famotidine and risk of COVID-19 outcomes (In Press) American Journal of Gastroenterology.

Singanayagam, A., Glanville, N., Girkin, J.L., Ching, Y.M., Marcellini, A., Porter, J.D., et al. (2018). Corticosteroid suppression of antiviral immunity increases bacterial loads and mucus production in COPD exacerbations. Nat Commun 9(1), 2229. doi: 10.1038/s41467-018-04574-1.

Su, Y., Yuan, D., Chen, D.G., Wang, K., Choi, J., Dai, C.L., et al. (2021). Heterogeneous immunological recovery trajectories revealed in post-acute COVID-19. medRxiv, 2021.2003.2019.21254004. doi: $10.1101 / 2021.03 .19 .21254004$.

Sun, S., Chen, Y., Hu, L., Wu, Y., Liang, M., Ahmed, M., et al. (2021). Does Famotidine reduce the risk of progression to severe disease, death, and intubation for COVID-19 patients? A systemic review and metaanalysis. (E pub ahead of print) Digestive Diseases and Sciences. doi: 10.1007/s10620-021-06872-z.

Tang, N., Li, D., Wang, X., and Sun, Z. (2020a). Abnormal coagulation parameters are associated with poor prognosis in patients with novel coronavirus pneumonia. J Thromb Haemost 18(4), 844-847. doi: $10.1111 /$ jth. 14768 .

Tang, S., Sun, R., Xiao, Q., Mao, T., Ge, W., Huang, C., et al. (2020b). Proteomics Uncovers Immunosuppression in COVID-19 Patients with Long Disease Course. medRxiv, 2020.2006.2014.20131078. doi: 10.1101/2020.06.14.20131078.

Thomas, B.J., Porritt, R.A., Hertzog, P.J., Bardin, P.G., and Tate, M.D. (2014). Glucocorticosteroids enhance replication of respiratory viruses: effect of adjuvant interferon. Sci Rep 4, 7176. doi: 10.1038/srep07176.

Tian, S., Hu, N., Lou, J., Chen, K., Kang, X., Xiang, Z., et al. (2020). Characteristics of COVID-19 infection in Beijing. J Infect 80(4), 401-406. doi: 10.1016/j.jinf.2020.02.018.

Tomera, K., and Kittah, J. (2020). Anosmia in COVID-19: Celecoxib Appears to Speed Recovery. Journal of Pharmacology, Pharmaceutics \& Pharmacovigilance 4.

Tomera, K., Malone, R., and Kittah, J. (2020). Brief Report: Rapid Clinical Recovery from Severe COVID-19 with High Dose Famotidine and High Dose Celecoxib Adjuvant Therapy. Enliven: Pharmacovigilance and Drug Safety 6.

Tomera, K., Malone, R., and Kittah, J. (2021). Hospitalized COVID-19 Patients Treated With Celecoxib and High Dose Famotidine Adjuvant Therapy Show Significant Clinical Responses. (In Press) Frontiers in Pharmacology. 
Vabret, N., Britton, G.J., Gruber, C., Hegde, S., Kim, J., Kuksin, M., et al. (2020). Immunology of COVID-19: Current State of the Science. Immunity 52(6), 910-941. doi: 10.1016/j.immuni.2020.05.002.

Wendel Garcia, P.D., Fumeaux, T., Guerci, P., Heuberger, D.M., Montomoli, J., Roche-Campo, F., et al. (2020). Prognostic factors associated with mortality risk and disease progression in 639 critically ill patients with COVID-19 in Europe: Initial report of the international RISC-19-ICU prospective observational cohort. EClinicalMedicine, 100449. doi: https://doi.org/10.1016/j.eclinm.2020.100449.

Wong, J.J.M., Leong, J.Y., Lee, J.H., Albani, S., and Yeo, J.G. (2019). Insights into the immunopathogenesis of acute respiratory distress syndrome. Ann Transl Med 7(19), 504. doi: 10.21037/atm.2019.09.28.

Yan, X., Hao, Q., Mu, Y., Timani, K.A., Ye, L., Zhu, Y., et al. (2006). Nucleocapsid protein of SARS-CoV activates the expression of cyclooxygenase-2 by binding directly to regulatory elements for nuclear factor-kappa B and CCAAT/enhancer binding protein. Int J Biochem Cell Bio/38(8), 1417-1428. doi: 10.1016/j.biocel.2006.02.003.

Zhang, L., Yan, X., Fan, Q., Liu, H., Liu, X., Liu, Z., et al. (2020). D-dimer levels on admission to predict inhospital mortality in patients with Covid-19. J Thromb Haemost 18(6), 1324-1329. doi: $10.1111 /$ jth.14859.

Zhou, F., Yu, T., Du, R., Fan, G., Liu, Y., Liu, Z., et al. (2020). Clinical course and risk factors for mortality of adult inpatients with COVID-19 in Wuhan, China: a retrospective cohort study. Lancet 395(10229), 10541062. doi: 10.1016/S0140-6736(20)30566-3.

Zhu, J., Ji, P., Pang, J., Zhong, Z., Li, H., He, C., et al. (2020). Clinical characteristics of 3062 COVID-19 patients: A meta-analysis. J Med Viro/92(10), 1902-1914. doi: 10.1002/jmv.25884.

\section{Figures}




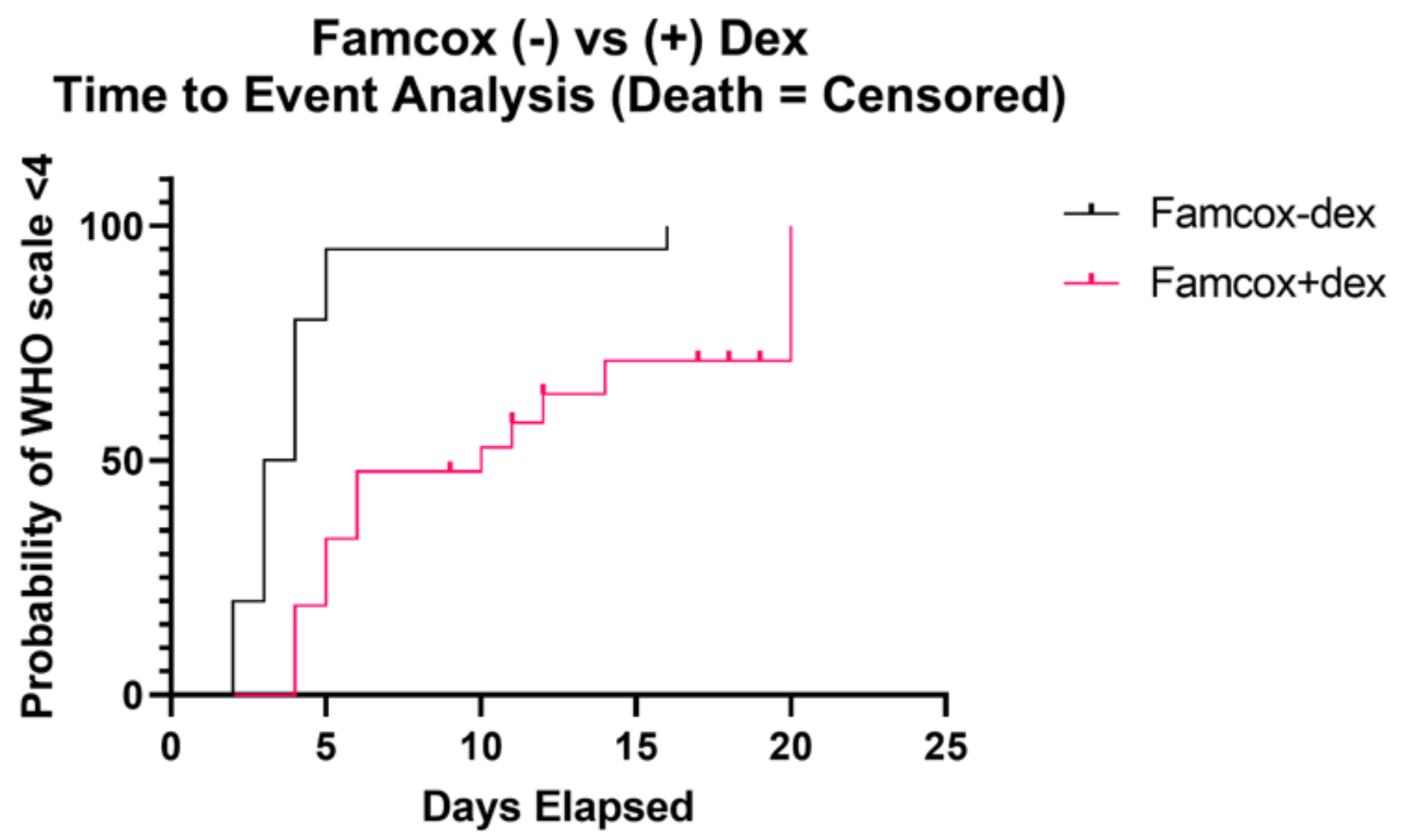

Figure 1

Time to event analysis, WHO Grade 3 or less Kaplan-Meir staircase plot summarizing time to event analysis for progression to WHO category 3 or less $(\mathrm{WHO}<4)$ for control cohort (famcox without dexamethasone) and experimental cohort (famcox with dexamethasone). Data are plotted with censored death events designated as upward ticks associated with the respective plot line. Log-rank (Mantel-Cox) curve comparison indicates statistically significant differences (chi squared value 21.46, $P<0.0001$. Gehan-Breslow-Wilcoxian test of differences chi squared value $21.46, P<0.0001$. 
A

Supplemental Oxygen Use

$(-)$ Dex

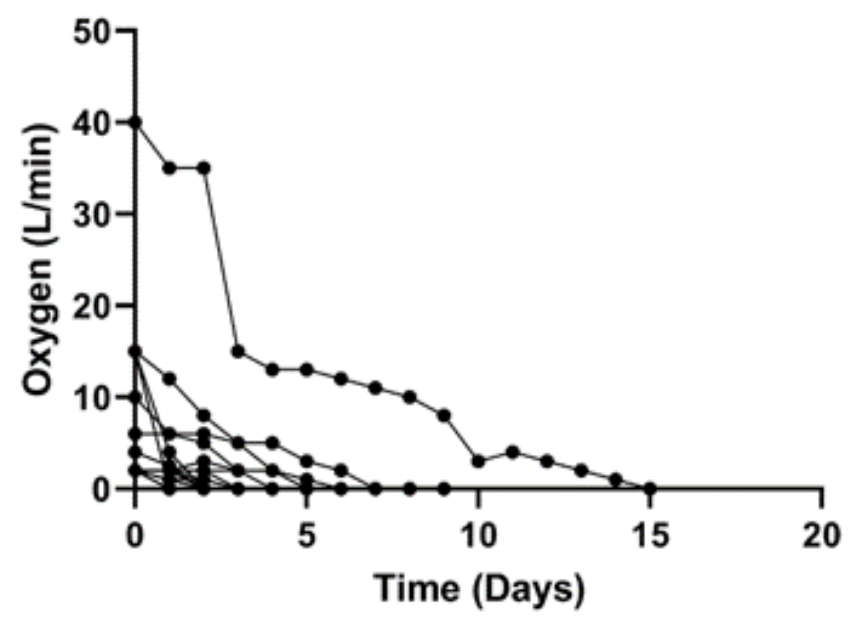

B

Supplemental Oxygen Use

(+) Dex

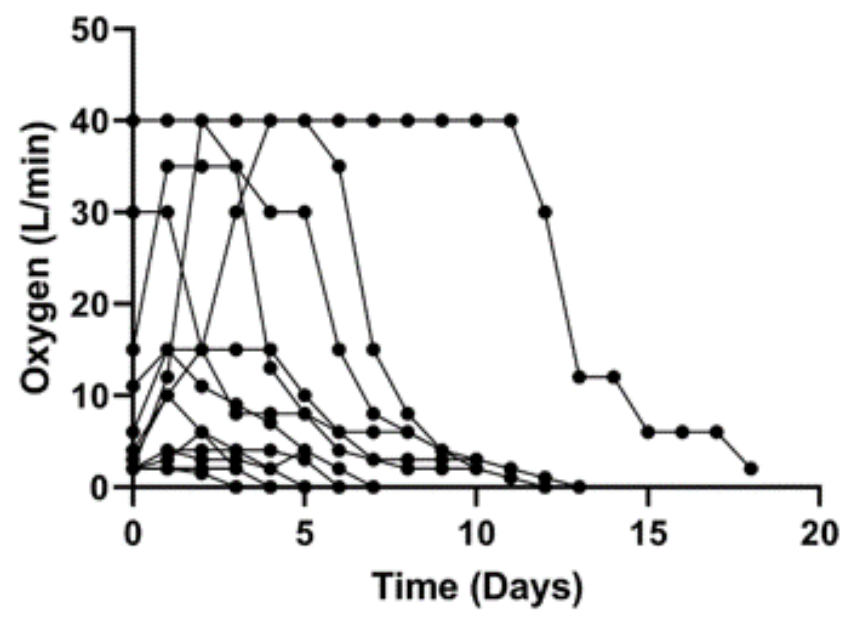

Figure 2

Comparison of oxygen usage over time by treatment cohort Summary line plots of oxygen usage trends for all patients, censored for intubation or death. Panel A summarizes control group supplemental oxygen usage over time (famcox without dexamethasone). Panel B summarizes experimental group supplemental oxygen usage over time (famcox with dexamethasone).

\section{C-Reactive Protein}

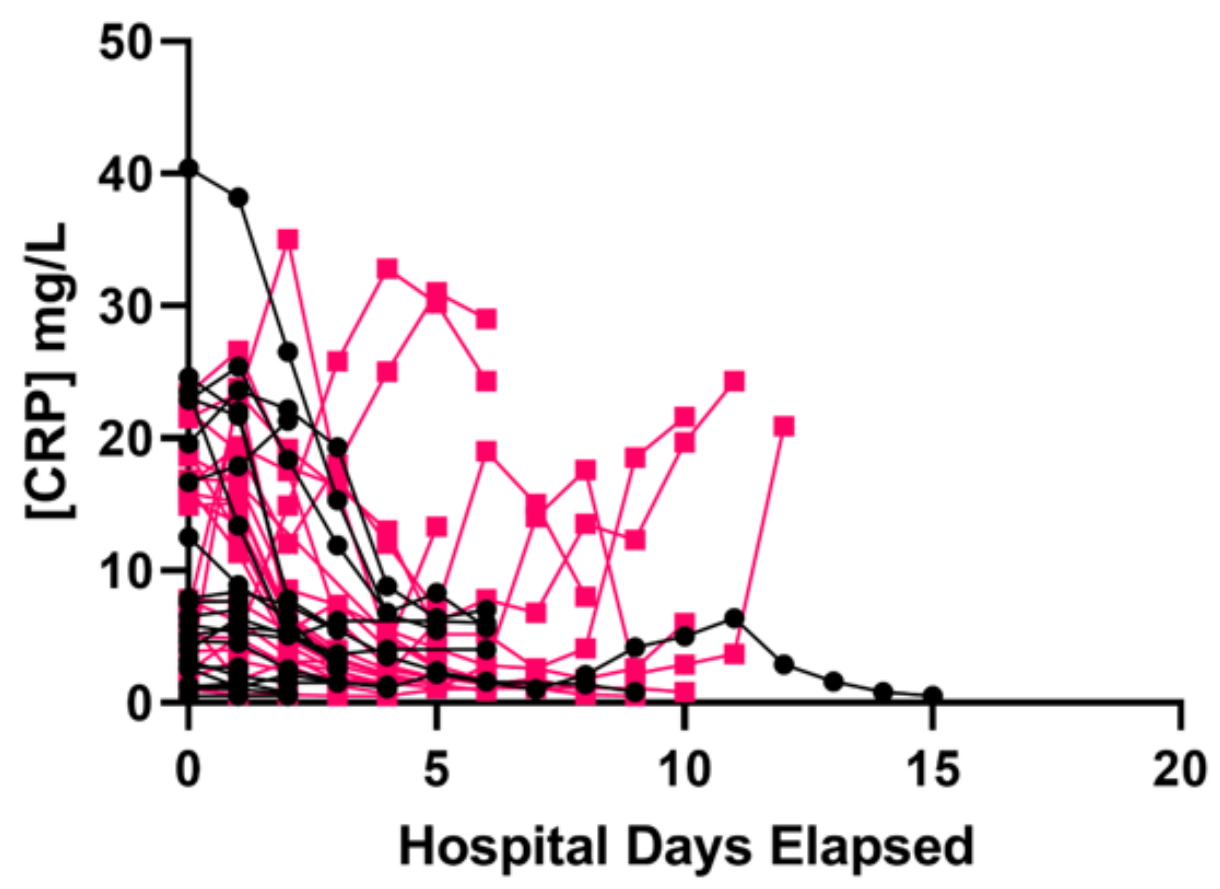

$\rightarrow \quad(-)$ Dex

$\rightarrow-(+)$ Dex

Figure 3 
Comparison of serum C-reactive protein concentrations over time Combined line plot of serum C-reactive protein serum biomarker concentrations as a function of time for both control (famcox without dexamethasone, black lines) and experimental (famcox with dexamethasone, red lines) treatment groups.
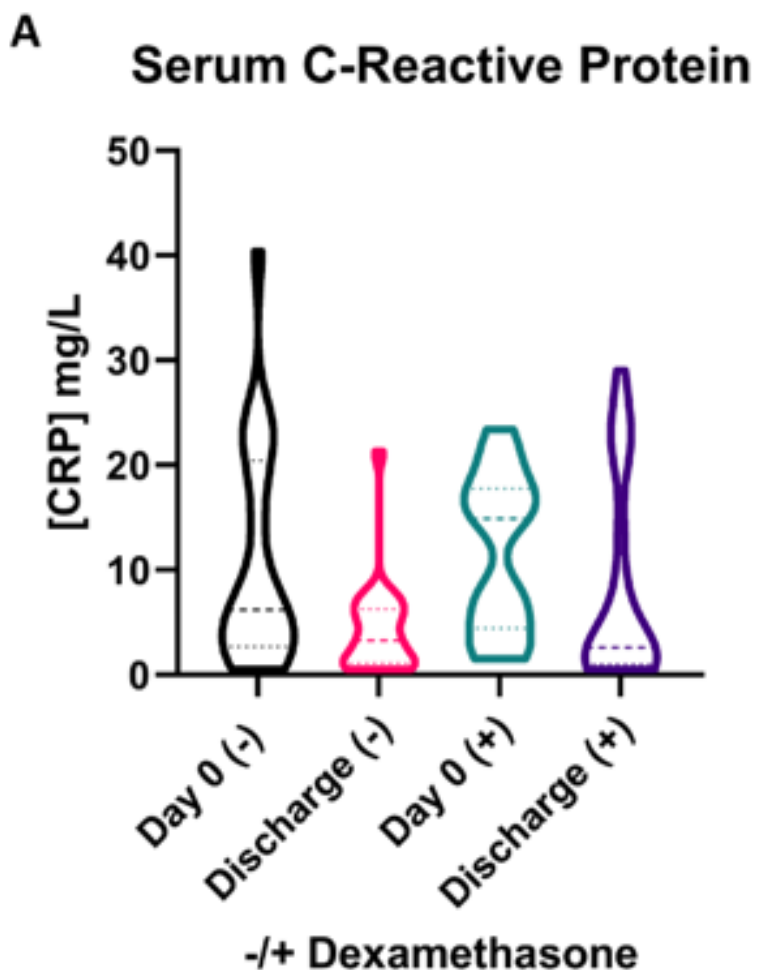

B Serum Lactate Dehydrogenase
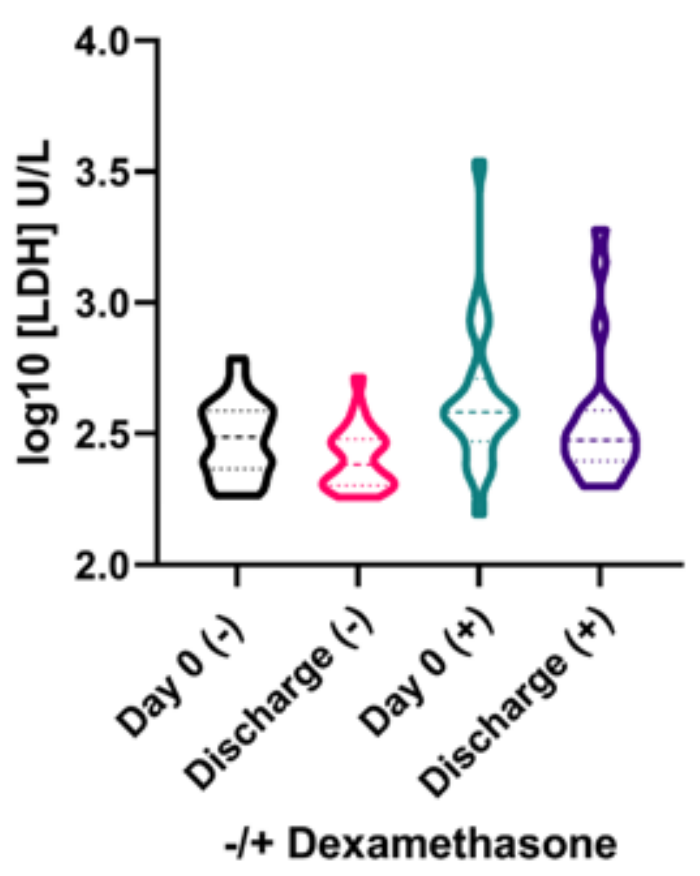

C

Serum Ferritin

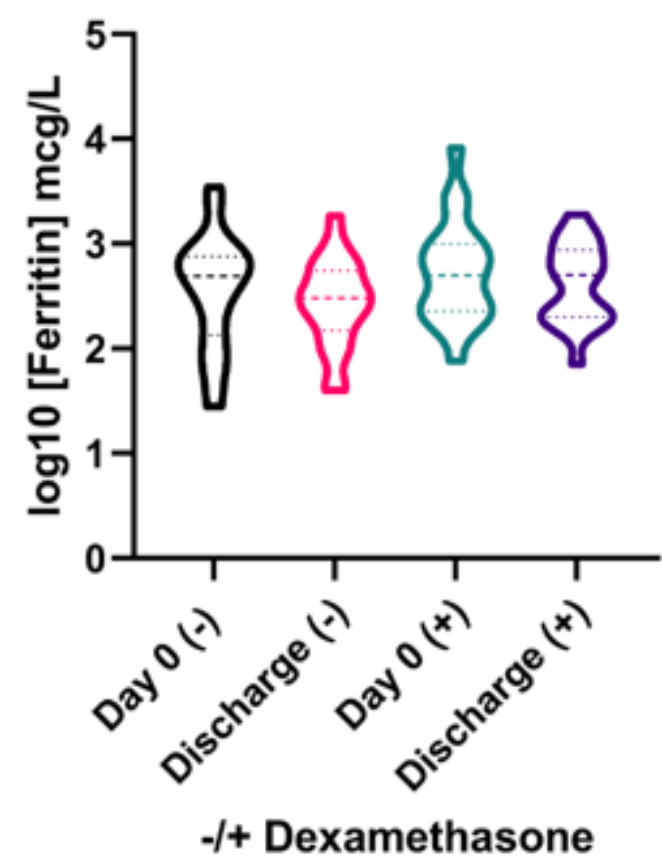

Figure 4

Inflammatory biomarker analysis Violin plots summarizing results of serum inflammatory biomarker test results. Larger dashed line represents the median value, dotted lines represent upper and lower standard 
deviations from the mean. Day 0 represents day of initial enrollment in the study. Discharge reflects last data point available (prior to either discharge or death, as appropriate). (-) indicates control group values; group treated with famcox without dexamethasone. (+) indicates experimental group values; group treated with famcox as well as with dexamethasone. Serum C-reactive protein values summarized in panel A, log 10 transformed serum lactate dehydrogenase values summarized in panel B, log 10 transformed serum ferritin values summarized in panel C. Logarithmic transformation performed to support plot clarity while including all values due to inclusion of outlier values in the overall plot.

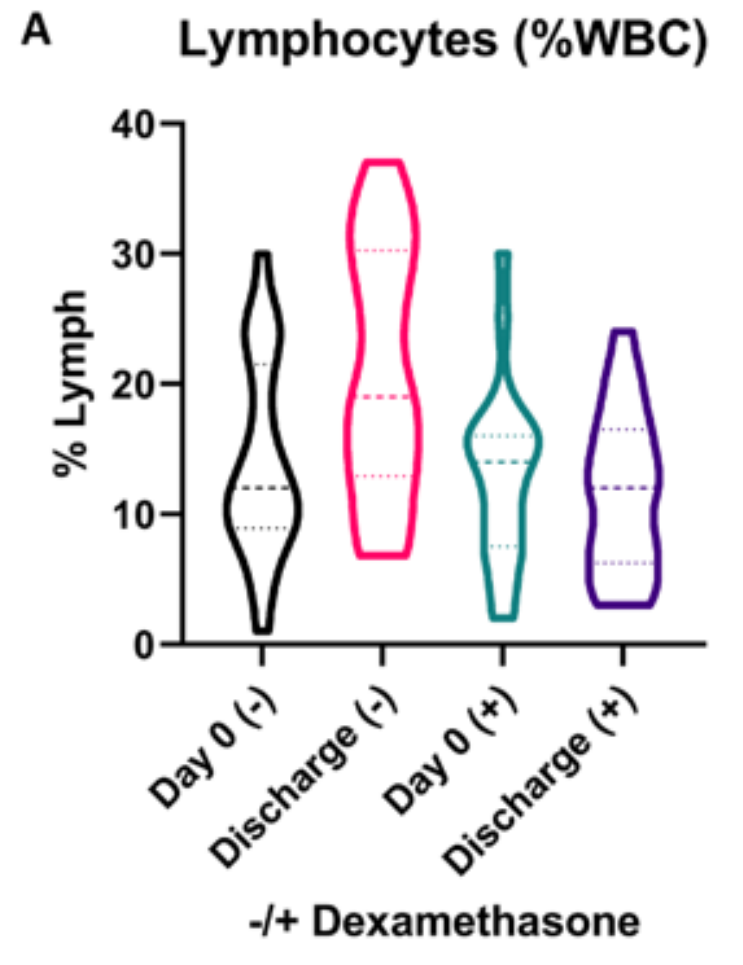

C
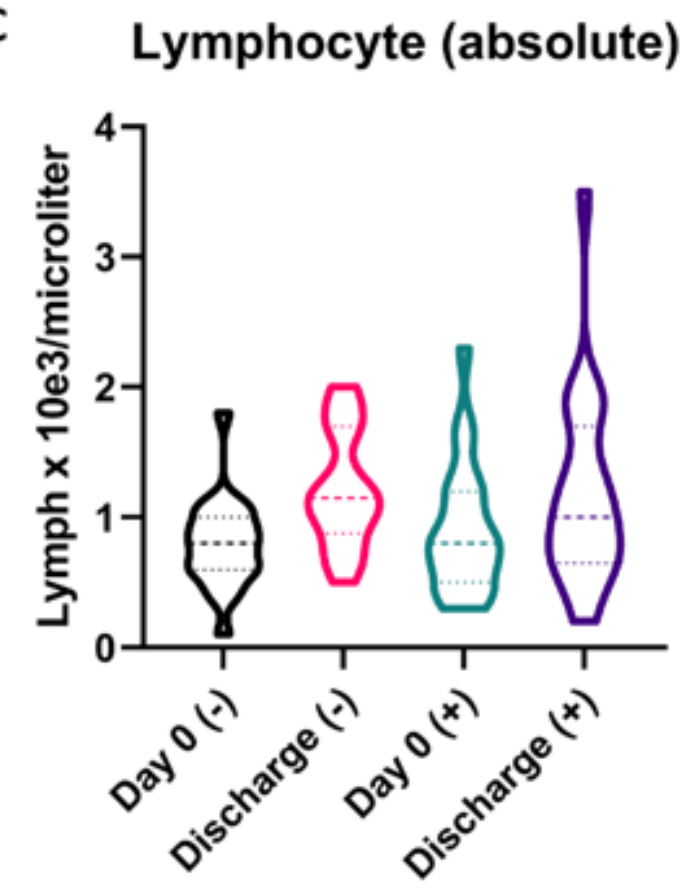

-/+ Dexamethasone
B Absolute Neutrophil Count

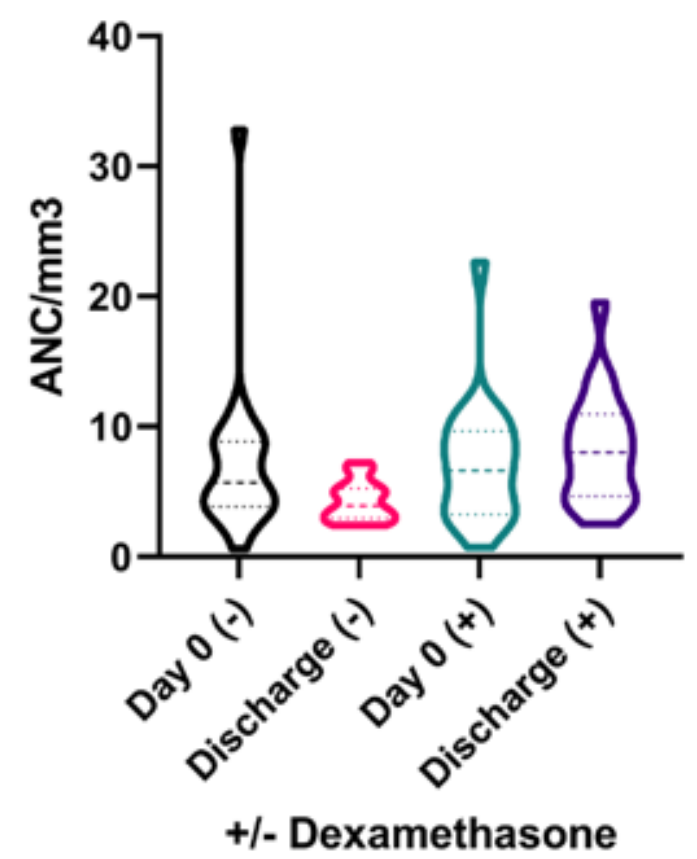

D Neutrophil/Lymphocyte Ratio
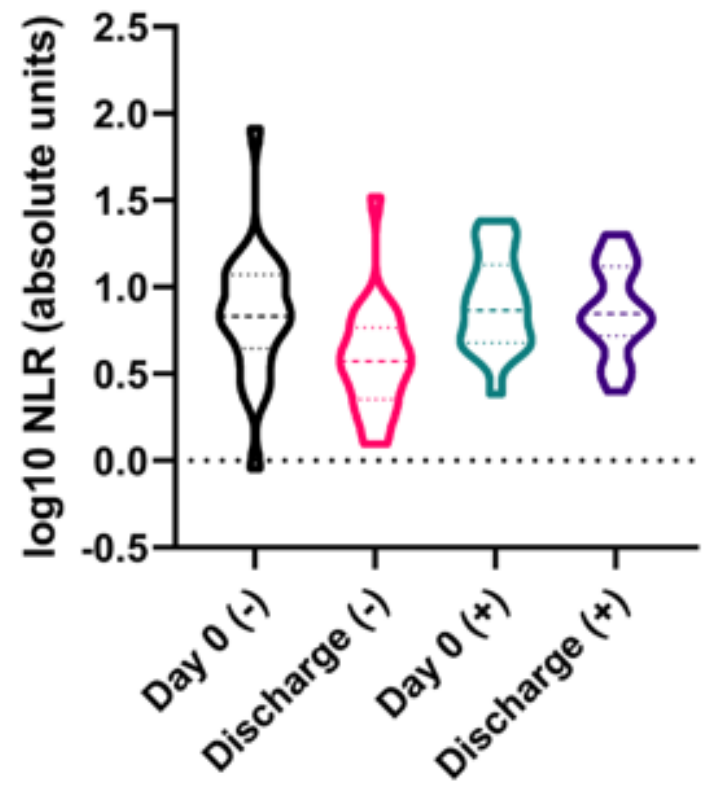

-/+ Dexamethasone 


\section{Figure 5}

Hematologic biomarker analysis Violin plots summarizing results of serum hematologic biomarker test results. Larger dashed line represents the median value, dotted lines represent upper and lower standard deviations from the mean. Day 0 represents day of initial enrollment in the study. Discharge reflects last data point available (prior to either discharge or death, as appropriate). (-) indicates control group values; group treated with famcox without dexamethasone. (+) indicates experimental group values; group treated with famcox as well as with dexamethasone. Panel A represents the lymphocyte count reported as a percentage of total white blood cells. Panel B represents the absolute neutrophil count (ANC) per cubic millimeter $(\mathrm{ml})$ of blood. Panel $\mathrm{C}$ represents the absolute lymphocyte count (ALC) per cubic millimeter $(\mathrm{ml})$ of blood. Panel D summarized the log 10 transformed neutrophil to lymphocyte ratio. Logarithmic transformation performed to support plot clarity while including all values due to inclusion of outlier values in the overall plot.

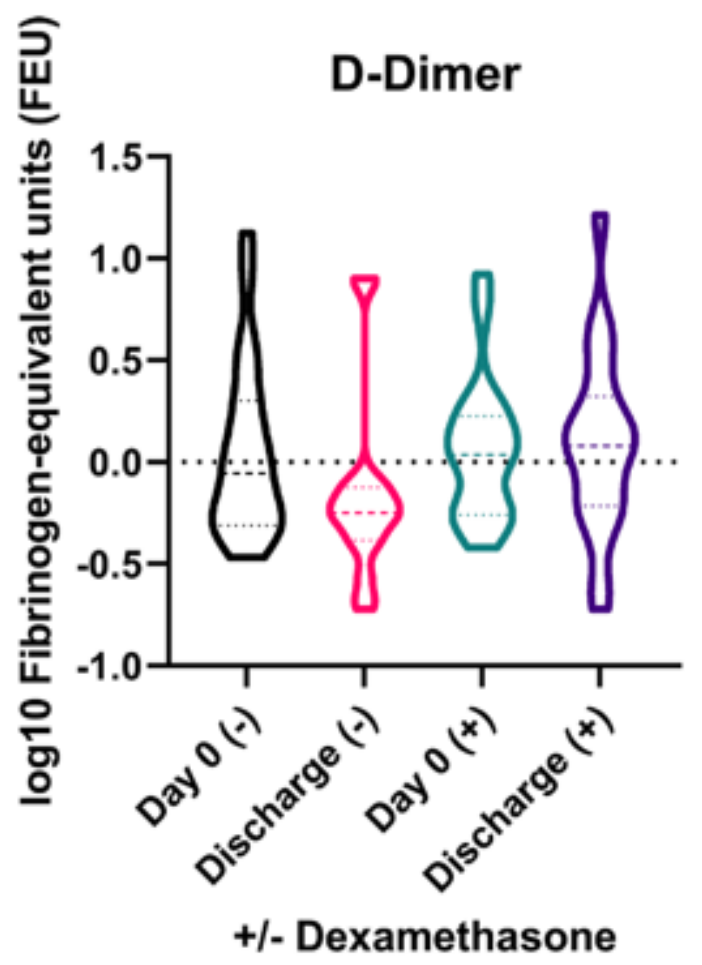

\section{Figure 6}

Coagulopathy biomarker Violin plots summarizing results of serum coagulopathy biomarker test results. Larger dashed line represents the median value, dotted lines represent upper and lower standard deviations from the mean. Day 0 represents day of initial enrollment in the study. Discharge reflects last data point available (prior to either discharge or death, as appropriate). (-) indicates control group values; group treated with famcox without dexamethasone. (+) indicates experimental group values; group treated with famcox as well as with dexamethasone. Measured D-dimer values are summarized as log 10 transformed data and are expressed as fibrinogen-equivalent units. Logarithmic transformation 
performed to support plot clarity while including all values due to inclusion of outlier values in the overall plot.

A

eGFR

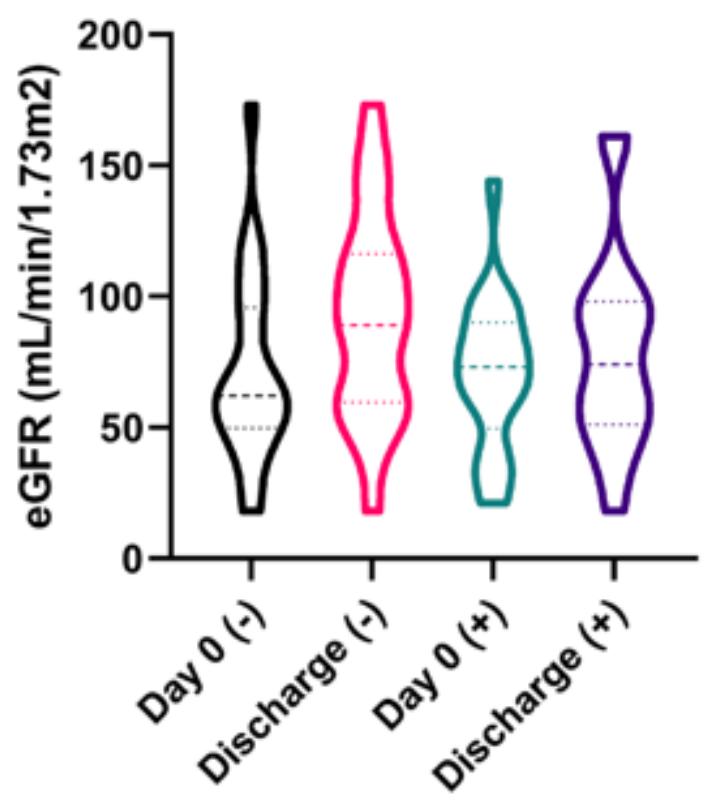

$(-/+)$ Dexamethasone
B

Serum Creatinine
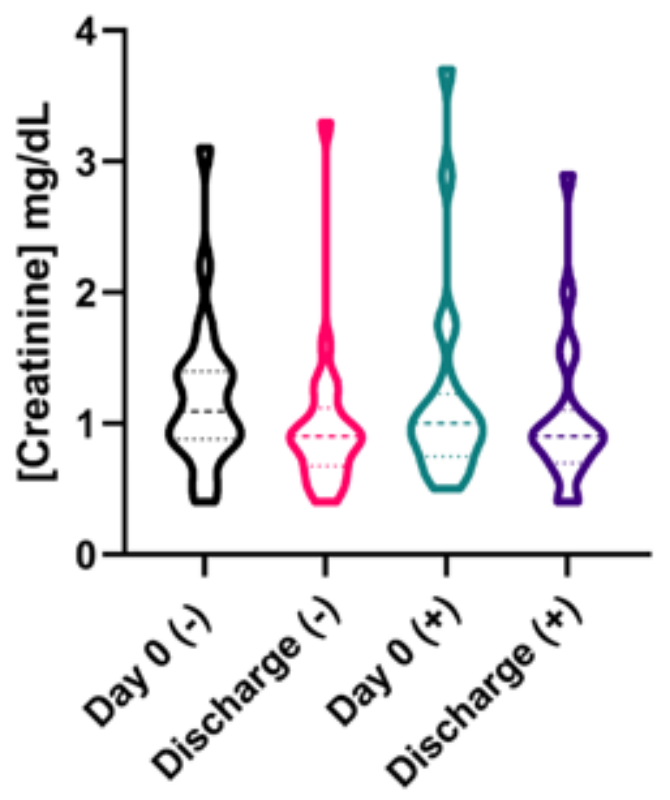

$(-/+)$ Dexamethasone

Figure 7

Renal function biomarkers Violin plots summarizing results of serum renal function biomarker test results. Larger dashed line represents the median value, dotted lines represent upper and lower standard deviations from the mean. Day 0 represents day of initial enrollment in the study. Discharge reflects last data point available (prior to either discharge or death, as appropriate). (-) indicates control group values; group treated with famcox without dexamethasone. (+) indicates experimental group values; group treated with famcox as well as with dexamethasone. Panel A summarizes the distribution of estimated glomerular filtration rate (eGFR). Panel B summarized the distribution of serum creatinine values. 
A Aspartate Aminotransferase

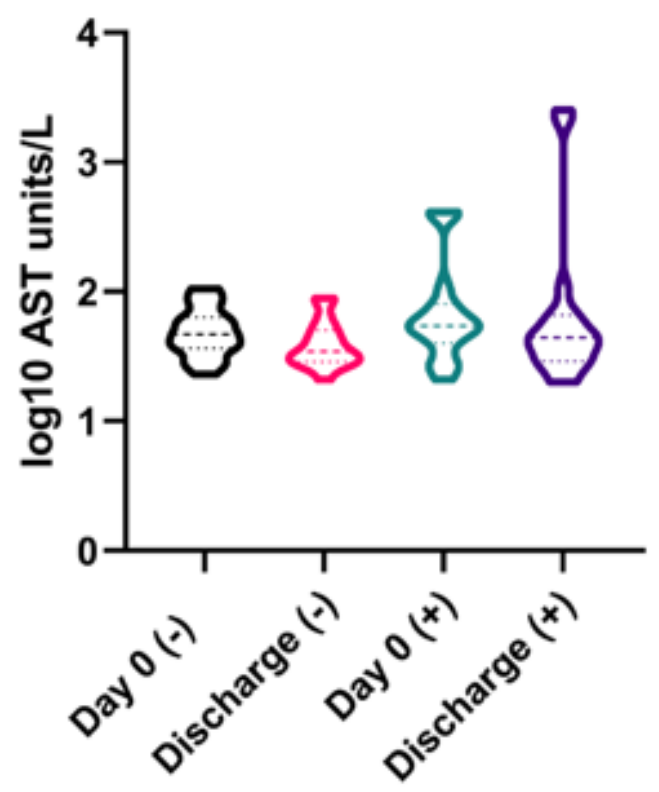

(-/+) Dexamethasone
B Total Biliruben
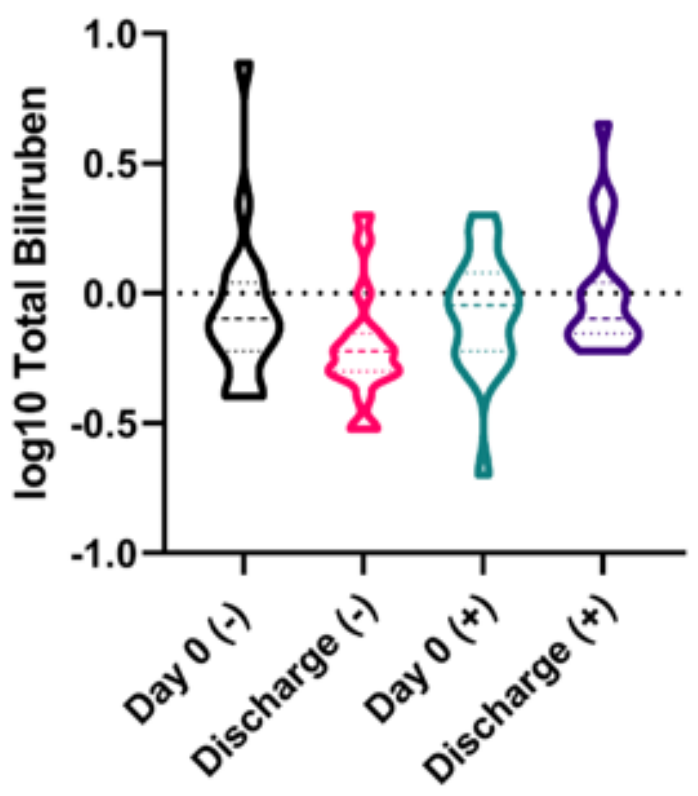

(-/+) Dexamethasone

Figure 8

Hepatic damage biomarkers Violin plots summarizing results of serum hepatic damage biomarker test results. Larger dashed line represents the median value, dotted lines represent upper and lower standard deviations from the mean. Day 0 represents day of initial enrollment in the study. Discharge reflects last data point available (prior to either discharge or death, as appropriate). (-) indicates control group values; group treated with famcox without dexamethasone. $(+)$ indicates experimental group values; group treated with famcox as well as with dexamethasone. Panel A summarizes log 10 transformed serum aspartate aminotransferase (AST) values. Panel B summarizes log 10 transformed total serum bilirubin values. Logarithmic transformation performed to support plot clarity while including all values due to inclusion of outlier values in the overall plot. 

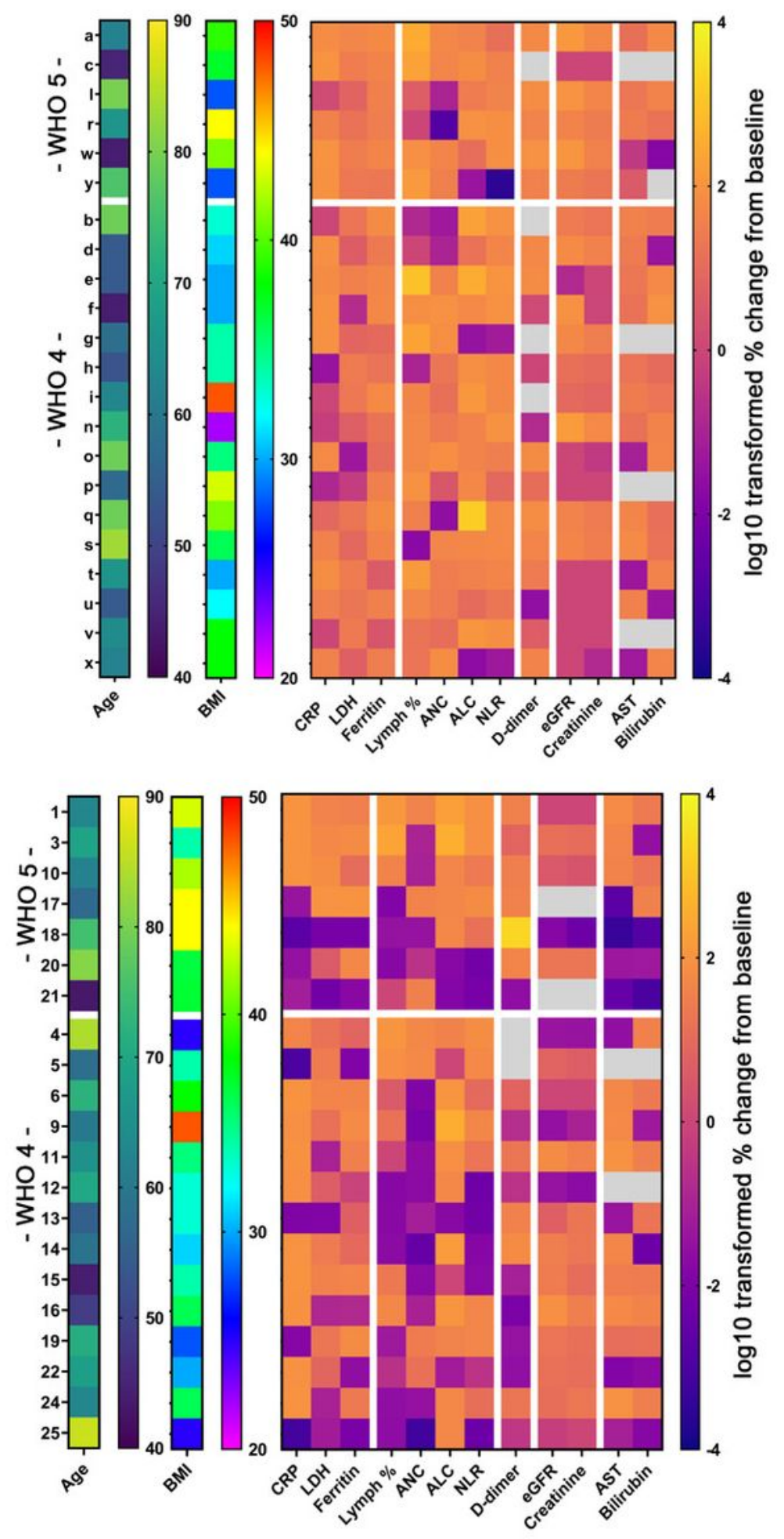

\section{Figure 9}

Heatmap of individual biomarker analysis (Top panel) Figure 9a provides an overview heatmap plot of control group (famcox without dexamethasone) biomarker data, and 9b summarizes the experimental cohort (famcox with dexamethasone) biomarker results. To facilitate heatmap display, the pre-and posttreatment laboratory biomarker data were normalized to yield percent change relative to baseline expressed as log 10 transformed ratios of pre-treatment value divided by post-treatment value. Log 10 
transformation was performed to support heat map analysis and plotting due to outlier values. After transformation, the sign of the change (positive if improved, negative if deteriorated) was added prior to plotting. Data are sorted and grouped by WHO score at time admission into the study (WHO 4 or 5). Heatmap plots corresponding to patient code are included for risk factors of age and body mass index (BMI). Laboratory biomarkers clustered (left to right) into inflammatory, hematologic, coagulopathy, renal function and hepatic damage biomarker groups corresponding to tests summarized in Figures 3-8. Gray color panels indicate missing data due to lack of testing during hospitalization. 